\begin{tabular}{|c|c|}
\hline Citation & $\begin{array}{l}\text { Gielen M, Vanhorebeek I, (2014), } \\
\text { Amino acid concentrations in critically ill children following cardiac } \\
\text { surgery*. } \\
\text { Pediatr Crit Care Med. } 2014 \text { May;15(4):314-28 }\end{array}$ \\
\hline Archived version & $\begin{array}{l}\text { Author manuscript: the content is identical to the content of the published } \\
\text { paper, but without the final typesetting by the publisher }\end{array}$ \\
\hline Published version & http://dx.doi.org/10.1097/PCC.0000000000000075 \\
\hline Journal homepage & http:/pccmjournal.com \\
\hline Author contact & $\begin{array}{l}\text { your email greet.vandenberghe@med.kuleuven.be } \\
\text { your phone number + } 32(0) 16344021\end{array}$ \\
\hline IR & https://lirias.kuleuven.be/handle/123456789/426448 \\
\hline
\end{tabular}

(article begins on next page) 


\title{
Amino acid concentrations in critically ill children following cardiac surgery
}

\author{
Marijke Gielen, MD, PhD, ${ }^{1,3}$ Ilse Vanhorebeek, $\mathrm{PhD},{ }^{1,3}$ \\ Pieter J Wouters, MSc, ${ }^{1}$ Dieter Mesotten, MD, PhD, ${ }^{1}$ Jan Wernerman, MD, PhD, ${ }^{2}$ \\ Greet Van den Berghe, MD, $\mathrm{PhD},{ }^{1}$ Olav Rooyackers, $\mathrm{PhD}^{2}$
}

${ }^{1}$ Clinical Department and Laboratory of Intensive Care Medicine, Division of Cellular and Molecular Medicine, KU Leuven, B-3000 Leuven, Belgium; ${ }^{2}$ Department of Anaesthesiology and Intensive Care, Karolinska University Hospital and Department of Clinical Science Intervention and Technology, CLINTEC, The Karolinska Institutet, SE-141 86 Huddinge, Sweden; ${ }^{3}$ equally contributed

\section{Correspondence and reprint requests to (no reprints will be ordered):}

Ilse Vanhorebeek, PhD, Laboratory of Intensive Care Medicine, Cellular and Molecular Medicine, KU Leuven, B-3000 Leuven, Belgium, Phone +32-16-344021, Fax +32-16-344015, e-mail ilse.vanhorebeek@med.kuleuven.be

Conflicts of Interest: The authors have no conflict of interest to report.

\section{Source of Funding:}

Supported by the TBM program of the Institute for Science and Technology - Flanders, Belgium (IWT 070695), the Swedish Medical Research Council (projects 04210 and 14244) and the Country Council of Stockholm (projects 502033 and 511126). MG received a Research Foundation-Flanders (FWO) Research Assistant Fellowship. GVdB by the University of Leuven receives structural research financing via the Methusalem program, funded by the Flemish Government, and holds an ERC Advanced grant (AdvG-2012-321670) from the Ideas Program of the EU FP7.

Key words: critical illness, pediatrics, amino acids, insulin, glucose control, mortality 


\section{ABSTRACT}

Objective: Guidelines for administering amino acids to critically ill children are largely based on uncontrolled observational studies and expert opinion, without support from rigorous outcome studies. Also, data on circulating amino acid concentrations during critical illness are scarce. We thoroughly studied the time profiles of circulating amino acid concentrations in critically ill children who received standard nutritional care according to international guidelines.

Design: This is a subanalysis of pediatric critically ill patients included in a large $(\mathrm{n}=700)$ randomized controlled study on intensive insulin therapy (IIT).

Setting: The study was conducted at a university hospital pediatric intensive care unit (PICU).

Patients: We studied 100 patients in PICU for at least 3 days following cardiac surgery.

Interventions: Patients were assigned to IIT targeting normal-for-age fasting blood glucose concentrations or insulin infusion only to prevent excessive hyperglycemia.

Measurements and Main Results: Plasma amino acid concentrations were measured upon admission, day 3 and day 7 in PICU. Upon admission, the concentrations of most amino acids were comparable to those reported for healthy children. Total amino acid concentrations remained stable during ICU stay, but individual amino acids showed different time profiles with 8 of them showing an increase and 5 a decrease. Non-surviving children had higher total amino acid concentrations and individual amino acids than survivors upon admission and/or during ICU stay. IIT lowered the concentrations of total amino acids and several individual amino acids. Neonates showed somewhat different amino acid profiles with rather increased concentrations from baseline with time in ICU for total amino acids and several individual amino acids as compared with older infants and children.

Conclusions: Circulating amino acid concentrations in critically ill children after cardiac surgery differ according to survival status, blood glucose control with IIT and age. 


\section{INTRODUCTION}

In current practice, mixed essential and non-essential amino acids are added to parenteral nutrition for critically ill patients. However, composition and timing of administration are largely based on uncontrolled observational studies and expert opinion (1-5). In this regard, protein requirements and demand for amino acids are thought to be higher during critical illness $(6,7)$. After an acute insult, catabolic pathways are strongly activated (8). Muscle proteins then constitute the major source of amino acid release to support increased amino acid demand as substrate for de novo protein synthesis, the immune/inflammatory system and wound healing, amongst others (6-10). When this hypercatabolic state is sustained with prolonged critical illness, profound erosion of lean tissue mass ensues, which has been associated with severe weakness and prolonged convalescence. Rigorous data on the efficacy of various amino acid formulations with regard to clinical outcome and optimal timing are needed to more specifically guide amino acid dosing in critically ill patients to minimize lean tissue loss and/or optimize amino acid availability for other processes (5). Safety also needs to be considered as administration of too high doses may induce toxicity (11). For critically ill children in particular, data are insufficient to guide macronutrient intake by evidence-based recommendations (4, 7). Whereas an aggressive early enteral nutrition protocol has shown to improve nitrogen balance in critically ill children (12), only limited data are available on plasma amino acid concentrations in this vulnerable patient population (13-15).

We performed a large randomized controlled study on the maintenance of age-adjusted normoglycemia with intensive insulin therapy (IIT) in critically ill children, showing prevention of serious intensive care unit (ICU) morbidity and reduced ICU mortality (16). Although the intervention strongly increased the incidence of brief hypoglycemia episodes, it did not cause any detectable harm to intelligence and even improved other areas of cognition (17). This study offered us the opportunity to thoroughly analyze time profiles of circulating amino acid concentrations in critically ill children. For this purpose, we selected a subgroup of cardiac surgery patients, who also received standardized nutritional care according to international guidelines (18). We first assessed whether there was a 
relation between individual amino acid concentrations and outcome, as such information could shed light on deficient or potentially toxic amino acid concentrations. Next, we studied the impact of IIT on the amino acid concentrations. Given that hyperglycemia promotes catabolism (19), that insulin is an anabolic hormone known to suppress amino acid release from muscle and to stimulate amino acid uptake (20), and that we previously demonstrated improved insulin sensitivity in skeletal muscle with IIT (21), we hypothesized that circulating amino acid concentrations would be lower in patients who received IIT. Finally, we evaluated whether the time profiles differed with age, as amino acid concentrations vary according to age in healthy children (22) and different nutritional recommendations are applied dependent on the critically ill patient's age (18). 


\section{MATERIALS AND METHODS}

Patients

We selected a subgroup of patients included in a large, prospective randomized controlled study on age-adjusted tight glycemic control with IIT in the pediatric ICU (PICU) (NCT00214916; Institutional Review Board approval number ML2586) (16). Written informed consent had been obtained from the patients' next-of-kin. For exclusion criteria and CONSORT diagram of the randomized study, we refer to the original report (16).

The patients had been randomly allocated to conventional insulin therapy (CIT) or IIT. CIT patients only received insulin when blood glucose concentrations exceeded $215 \mathrm{mg} / \mathrm{dL}(11.9 \mathrm{mmol} / \mathrm{L})$ twice, and the insulin dose was adjusted to keep blood glucose between 180-215 mg/dL (10.0-11.9 $\mathrm{mmol} / \mathrm{L}$ ). The insulin infusion was tapered down and stopped when the blood glucose concentration fell below $180 \mathrm{mg} / \mathrm{dL}$ (10.0 mmol/L). In the patients receiving IIT, insulin was continuously infused to control blood glucose concentrations within the age-adjusted normal fasting range of $50-80 \mathrm{mg} / \mathrm{dL}$ (2.8-4.4 mmol/L) for infants ( $<1$ year) and 70-100 mg/dL (3.9-5.6 mmol/L) for children (1-16 years) (23). Insulin infusion was started when the blood glucose concentration exceeded the upper limit of normal and the dose was adjusted to maintain concentrations within the defined targets.

For this subanalysis, we randomly selected 50 patients of the CIT group and 50 patients of the IIT group who were admitted to the PICU after major surgery for congenital heart defects and needed intensive care for at least 3 days (Fig. 1). In each group, we randomly selected 30 infants (of which 78 neonates $\leq 4$ weeks old) and 20 children. Furthermore, of the 50 patients in each group, 20 needed intensive care for at least 7 days. The patients were matched for age, BMI, gender, day 1 PEdiatric Logistic Organ Dysfunction (PELOD) score and Risk Adjustment in Congenital Heart Surgery (RACHS) score. These and other baseline characteristics are presented in Table 1 and Supplemental Digital Content Table 1. The children received (par)enteral nutrition according to the nutritional guidelines published by Shann et al. and described in detail in the original report $(16,18)$. Intake of individual amino acids and total caloric intake are described in Table 2. 


\section{Biochemical analyses}

Whole blood glucose concentrations were measured in arterial blood at 1-4 hour intervals (ABL700 blood gas analyzer, Radiometer Medical A/S, Copenhagen, Denmark). Arterial blood was systematically sampled upon admission (prior to initiation of feeding and glucose management) and daily at 6 a.m. during PICU stay. Plasma was kept frozen at $-80^{\circ} \mathrm{C}$ until analysis.

Amino acid concentrations were quantified in plasma samples taken upon admission and on day 3 and day 7 in PICU. Plasma sample sets were incomplete for 2 patients. The amino acids analyzed included alanine, arginine, asparagine, glutamine, glutamate, glycine, histidine, isoleucine, leucine, lysine, methionine, phenylalanine, serine, taurine, threonine, tryptophan, tyrosine and valine. Before HPLC analysis, plasma samples were deproteinized on ice by addition of $3 \%$ sulfosalicylic acid that contained $0.2 \mathrm{mM} \mathrm{L-norvaline} \mathrm{as} \mathrm{internal} \mathrm{standard,} \mathrm{followed} \mathrm{by} \mathrm{centrifugation} \mathrm{at} 600 \mathrm{~g}$ (20 minutes at $4^{\circ} \mathrm{C}$ ) and filtration of the supernatant through a $0.22 \mu \mathrm{m}$ membrane filter. The amino acids were derivatized with ortho-phtaldialdehyde/3-mercaptopropionic acid and the HPLC analyses of free amino acids were performed as described previously using a Ymc-packODS-AQ 150 x $4.6 \mathrm{~mm}$ column on a Waters 600E system with Waters 717plus autosampler (Waters SverigeAB, Sollentuna, Sweden) and 821 FP Jasco fluorescence detector (Mölndal, Sweden, excitation at $340 \mathrm{~nm}$ and emission at $450 \mathrm{~nm})(24)$.

\section{Statistical analysis}

Analyses were performed using Statview 5.0.1 (SAS Institute, Cary, NC). Differences between groups were assessed by Chi-square test (proportions), Student's t-test (normally distributed data), and Mann-Whitney U test (not-normally distributed data). Main effects between groups were analyzed by repeated measures ANOVA. $p \leq 0.05$ was considered statistically significant. 


\section{RESULTS}

Natural time course of the amino acid concentrations during ICU stay

We first compared amino acid concentrations in critically ill children upon ICU admission, prior to initiation of nutrition (Supplemental Digital Content Table 2), with those reported for different age groups (0-1, 1-4 and 5-15 years old) of healthy children in the post-absorptive state (22). The sum of all measured amino acids (total amino acids) appeared elevated upon admission. Concentrations of asparagine and tyrosine were lower, while concentrations of glutamate, lysine, methionine, phenylalanine and tryptophan were higher. The sum of branched-chain amino acids (BCAA) was also higher, although individual concentrations of isoleucine, leucine and valine were not clearly elevated.

Amino acid measurements at baseline, day 3 and day 7 showed that concentrations of isoleucine, methionine, phenylalanine, serine, valine and essential amino acids (EAA) increased from baseline towards day 3, irrespective of length of stay, and returned to lower concentrations by day 7 , except for methionine that increased further and serine and EAA that remained stable at elevated concentrations (Fig. 2). Arginine and threonine concentrations remained stable until day 3 and increased towards day 7, whereas glycine concentrations gradually increased towards day 3 and day 7 . Concentrations of alanine, asparagine, glutamine, glutamate and taurine decreased by day 3. Except for a return to higher concentrations for glutamine, concentrations remained stable until day 7 . Concentrations of histidine, leucine, lysine, tryptophan, tyrosine, total BCAA, and total amino acids did not change during ICU stay. Plasma concentrations of the individual amino acids in general did not systematically correlate with intake of the respective amino acids, except for glutamate (day 3: $\mathrm{r}^{2}=0.117, p=0.0006$ : day $7: \mathrm{r}^{2}=0.193, p=0.005$ ) and taurine (day $3: \mathrm{r}^{2}=0.134, p=0.0002$ : day 7 : $\left.\mathrm{r}^{2}=0.242, p=0.001\right)$. 
To gain insight in potential deficiency or toxicity of individual amino acid concentrations during critical illness, we compared their baseline concentrations and profiles in survivors and nonsurvivors. In non-survivors, already upon ICU admission, several amino acids were higher than in survivors, including alanine $(p<0.0001)$, glutamate $(p=0.05)$, histidine $(p=0.001)$, lysine $(p=0.05)$, phenylalanine ( $p=0.02$ ), and the sum of all measured amino acids ( $p=0.008$ ) (Supplemental Digital Content Table 2). Time profiles could not be reliably compared for patients with an ICU stay shorter than 7 days (1 non-survivor versus 59 survivors). In patients who stayed in ICU for at least 7 days, the time course of amino acid concentrations from admission to day 7 overall was not affected by ICU survival state (Fig. 3). Only for leucine, different time profiles suggested an increase from baseline in the non-survivors and a decrease in survivors. Notwithstanding the absence of significant differences in the time profiles the concentrations of most amino acids were higher at day 3 and/or day 7 in nonsurvivors than in survivors in univariable analysis (Supplemental Digital Content Table 2). Amino acid intake on day 3 and 7 in ICU was comparable in survivors and non-survivors (Table 2).

\section{Impact of intensive insulin therapy on amino acid concentrations}

To address our hypothesis that circulating amino acid concentrations would be lowered by strict blood glucose control with IIT, we compared their time profiles for the patients randomized to CIT versus IIT. Baseline amino acid concentrations were comparable for patients in the CIT and IIT groups, except for glycine $(p=0.04)$, methionine $(p=0.02)$ and threonine $(p=0.04)$ for which the concentrations were higher in IIT patients (Supplemental Digital Content Table 2). IIT did not affect the time course of amino acid concentrations in patients who stayed less than 7 days in ICU, except for histidine, which had increased on day 3 compared to the admission value in IIT patients, while the concentration decreased in CIT patients (Fig. 4). In CIT patients who stayed in ICU for at least 7 days arginine, glutamate, lysine, threonine, BCAA, EAA, non-essential amino acids (not shown) and the sum of all amino acids increased, whereas this rise was suppressed by IIT. The concentrations of asparagine, glutamine and leucine did not change with time in the CIT group, but were lowered by 
IIT. IIT had no clear effect on the other amino acids. Patients in the CIT and IIT groups had a comparable amino acid intake on day 3 and 7 in ICU (Table 2).

\section{Amino acid concentrations in neonates versus older infants and children}

We addressed the impact of age on the amino acids by comparing their concentrations and profiles in neonates versus older infants and children. In neonates, admission concentrations of alanine ( $p=0.004)$, glycine $(p<0.0001)$, methionine $(p=0.04)$, serine $(p=0.01)$ and threonine $(p<0.0001)$ were higher, while admission concentrations of arginine $(p=0.01)$ and glutamine $(p=0.05)$ were lower as compared to older infants and children (Supplemental Digital Content Table 2). The time course of the amino acid concentrations did not differ between these age groups in patients with an ICU stay shorter than 7 days except for threonine, which decreased from admission to day 3 in neonates while there was no change in the older infants and children (Fig. 5). In neonates who stayed at least 7 days in ICU, concentrations of glutamate, leucine, valine and BCAA increased from admission to day 7, while these concentrations decreased in older infants and children. For isoleucine, the increase from admission to day 3 and the following decrease from day 3 to day 7 was more pronounced in neonates compared to older infants and children. Arginine, EAA and the sum of all amino acids increased from admission to day 7 in neonates, while there was no change in older infants and children. No significant differences were found for the other individual amino acids. The intake in ICU of most amino acids was higher in the neonates as compared with the older infants and children (Table 2). 


\section{DISCUSSION}

Recommendations for protein intake in critically ill children are largely based on observational studies and expert opinion, and circulating concentrations of amino acids have rarely been measured in such patients (1-5). More detailed information on amino acid concentrations in critically ill children is thus needed as a start to better guide amino acid administration in these patients. In the present exploratory analysis, we observed that the concentrations of most amino acids in critically ill children upon admission to the ICU were in the range of those reported for healthy children. While following the nutritional recommendations by expert guidelines for protein/amino acid requirements the concentrations of 8 amino acids increased, whereas 5 appeared to decrease during ICU stay, without effect on the total amino acid concentration. In non-survivors, the sum of all amino acids, as well as the concentrations of several individual amino acids, were higher during intensive care than in patients who would survive critical illness. Intensive insulin therapy lowered the concentrations of total amino acids and of 7 individual amino acids. Neonates showed somewhat different amino acid concentrations upon ICU admission and these concentrations rather increased from baseline for total and several individual amino acid concentrations during intensive care as compared with older infants and children. The impact of survival status, intensive insulin therapy and age was particularly present in patients who needed intensive care for at least 7 days.

It has been argued that amino acid requirement is increased during critical illness to meet an increased demand as substrate for protein synthesis, wound healing and the immune/inflammatory system, amongst others, while minimizing lean tissue loss (6, 7). Following internationally recognized guidelines for protein/amino acid administration to critically ill children (18), we observed that the concentrations of asparagine and tyrosine were low upon admission and remained low or even further decreased during ICU stay. Vice versa, glutamate, lysine, methionine, phenylalanine, tryptophan and BCAA were elevated upon ICU admission and remained high or even further increased during ICU stay. In addition, the patients developed subnormal concentrations of taurine and supranormal concentrations of glycine, serine and threonine with time in ICU as compared to the concentrations reported for healthy children (22). The observed decreases or increases theoretically may point to an 
inadequately balanced composition of the adminstered amino acid formula, with some amino acids being too low in concentration (e.g. lack of asparagine and glutamine in the administered nutrition, as well as absent or low concentrations of taurine) and others too high for optimal use in vivo. However, circulating amino acid concentrations result from a complex balance between their consumption in different processes (e.g. protein synthesis, gluconeogenesis, synthesis of polyamines and nitric oxide) and entry into the plasma. The latter is not only determined by dietary intake, but also by de novo synthesis and release from protein breakdown. Thus, higher concentrations of amino acids also could be explained by increased protein breakdown, resulting from the hypercatabolic state of critical illness, which is insufficiently counteracted with feeding $(25,26)$.

We observed remarkable differences in amino acid concentrations according to survival status. Total amino acid concentrations and the concentrations of most individual amino acids were higher in non-survivors than in survivors, upon admission and/or during ICU stay. This could be explained by a more pronounced activation of catabolism in patients who would not survive, rather than a different amino acid intake, in line with hypercatabolism being an important risk factor for delayed recovery and death (26). Alternatively, the administered amino acid dose could have been excessive for these patients in particular, reaching a concentration of toxicity. Adverse effects have been reported for very high amino acid intake above $4 \mathrm{~g} / \mathrm{kg} /$ day, including azotemia, metabolic acidosis, and neurodevelopmental abnormalities (7, 27), but are rarely seen with intakes of 2-3 g/kg/day (28). Nevertheless, toxicity may be reached at lower concentrations, particularly when renal and/or hepatic function of the children is severely compromised (7). In that regard, the immaturity of amino acid degradation pathways, nitrogen excretory function of the kidneys, and lack of small intestinal metabolism put parenterally fed neonates at risk of amino acid toxicity (29). Increases in several amino acids in critically ill neonates after surgery for necrotizing enterocolitis correlated with disease severity, mirrored the degree of liver dysfunction and disturbed amino acid metabolism in liver and muscle, and were more pronounced in non-survivors than in survivors (30). Interestingly, in fed adult prolonged critically ill patients, we recently observed an autophagy-deficiency phenotype, of which the severity correlated with the amount of infused amino acids (31). Furthermore, we observed that 
giving parenteral nutrition to critically ill rabbits, especially when enriched in amino acids, suppressed autophagy (32). Autophagy serves a crucial cellular quality control function by clearance of damaged organelles and toxic large proteins and aggregates $(33,34)$. Fasting is its strongest physiological activator (35), whereas it is inhibited by feeding and particularly by amino acids (36). Excessive amino acids may thus compromise damage removal, which is required for recovery from organ failure and may as such increase the risk of death.

We hypothesized that the amino acid concentrations in patients randomized to IIT would be lower than those in patients who received CIT. Several individual amino acids as well as total amino acid concentration were indeed lower in IIT patients, but only for the subgroup who needed intensive care for at least 7 days. According to the randomization, IIT patients had lower blood glucose and higher insulin concentrations than CIT patients, which both may have contributed to lowering of the amino acid concentrations. Hyperglycemia has been associated with an increased rate of muscle protein catabolism in severely burned patients (19). In critically ill rabbits maintained hyperinsulinemic, hyperglycemia activated ubiquitin-proteasome activity as compared with normoglycemia (37). Treatment of hyperglycemia in cancer patients following major surgery also improved skeletal muscle protein and amino acid metabolism (38). A study in severely injured patients showed direct stimulation of muscle protein synthesis by hyperinsulinemia (39). Improved insulin sensitivity in muscle when patients' blood glucose concentrations are maintained normal during critical illness (21) may have played a role, as insulin resistance would interfere with the role of insulin as anabolic hormone that suppresses amino acid release from muscle while stimulating amino acid uptake (20). As amino acid concentrations on one hand are higher in non-survivors and on the other hand are lowered by IIT, this effect may have contributed to the better clinical outcome of the children who received this therapy (16). Effectively reaching age-adjusted normal fasting glycemia may be crucial to obtain clinical benefits as virtually unaltered circulating blood glucose in studies that targeted adult normal fasting ranges failed to convey clinical benefit $(40,41)$.

Neonates had higher plasma concentrations of several amino acids upon admission and/or during ICU stay than older infants and children. This may in part be explained by a higher intake of 
these amino acids according to the nutritional guidelines $(7,18)$, although a more severely activated catabolism cannot be excluded. Also in metabolically healthy children undergoing elective surgery an age-dependent distribution of plasma amino acid concentrations has been described, with characteristic patterns for individual amino acids $(22,42)$. A retrospective review that assessed intakes of parenteral amino acids for 116 critically ill children compared amino acid intake with breast milk amino acid content for infants, as golden standard, and with mixed muscle protein content in older children (4). This study showed that parenteral nutrition provided essential amino acids in higher amounts and non-essential amino acids in lower amounts than the recommended intake for healthy children and questioned the adequacy of the amounts of amino acids that are provided to critically ill children. As in that study, asparagine, glutamine and taurine intake was limited or absent in our study.

This exploratory analysis has some inherent limitations. The random subgroup of patients was selected from within the group of cardiac surgery patients only, precluding extrapolation to other types of critical illness and potentially introducing bias as not all patients were studied. We did not simultaneously measure the amino acid concentrations in age-matched healthy children. Comparisons of upon-ICU admission concentrations with values in healthy children were based on healthy reference ranges in the literature (measured in venous blood using the same method) and not with an internal control population. Furthermore, we cannot exclude that pre-surgical amino acid concentrations were subnormal and raised to normal healthy concentrations in response to the severe surgical stress nor potential bias by administration of fresh frozen plasma during or shortly after surgery. We did not make any distinction between enteral and parenteral administration of the amino acids, but amount of enteral intake was mostly negligible as compared to the parenteral intake. Apart from the impact of randomized blood glucose control interventions, all other differences among the compared groups merely reflect association and not causality. No specific feeding intervention was tested, nor were patients selected for amino acid intake, but standardized nutritional guidelines were followed. Thus, we cannot make any statement about how much of the amino acids are actually needed, especially in light of the recent findings in the large randomized EPaNIC study showing faster recovery and fewer complications with late initiation of parenteral nutrition to complete enteral 
nutrition as compared with early initiation (43). The observed differences in amino acid concentrations appear mostly not explained by respective intakes on the days of measurement, except for the observed association with age, as recommended amino acid intake is higher for neonates than for older children $(7,18)$. However, any impact of potential differences in pre-surgical nutritional intake cannot be excluded.

\section{CONCLUSIONS}

A nutritional strategy based on the recommendations by expert guidelines was associated with different responses in time of individual amino acids, with some of them increasing, whereas others decreased or remained stable. Higher concentrations of most amino acids were associated with mortality and strict glycemic control with IIT lowered concentrations of several individual amino acids and total amino acids. Higher, increasing concentrations in neonates as compared with older infants and children may be related to the higher recommended protein intake. Since amino acid profiles have rarely been measured in critically ill children, this large study (although mostly observational) provides important insight and, after confirmation in another observational study to avoid bias by chance, may serve as a basis for further nutritional intervention studies with fine-tuned amino acid compositions for critically ill children. 


\section{ACKNOWLEDGEMENTS}

We thank the clinical and nursing staff of the PICU for excellent patient care and protocol compliance. We thank Dr. L. Desmet for help in classifying cardiac surgery categories.

Supported by the TBM program of the Institute for Science and Technology - Flanders, Belgium (IWT 070695), the Swedish Medical Research Council (projects 04210 and 14244) and the Country Council of Stockholm (projects 502033 and 511126). MG received a Research FoundationFlanders (FWO) Research Assistant Fellowship. GVdB by the University of Leuven receives longterm structural research financing via the Methusalem program, funded by the Flemish Government and holds an "ERC Advanced Grant” (AdvG-2012-321670) from the Ideas Program of the European Union FP7. 


\section{REFERENCES}

1. Singer P, Berger MM, Van den Berghe G, et al: ESPEN Guidelines on Parenteral Nutrition: intensive care. Clin Nutr 2009; 28:387-400

2. Martindale RG, Mcclave SA, Vanek VW, et al: Guidelines for the provision and assessment of nutrition support therapy in the adult critically ill patient: Society of Critical Care Medicine and American Society for Parenteral and Enteral Nutrition: Executive Summary. Crit Care Med 2009; $37: 1757-1761$

3. Heyland DK, Dhaliwal R, Drover JW, Gramlich L, Dodek P: Canadian clinical practice guidelines for nutrition support in mechanically ventilated, critically ill adult patients. JPEN $J$ Parenter Enteral Nutr 2003; 27:355-373

4. Verbruggen S, Sy J, Arrivillaga A, Joosten K, van Goudoever J, Castillo L: Parenteral amino acid intakes in critically ill children: a matter of convenience. JPEN J Parenter Enteral Nutr 2010; 34:329-340

5. Yarandi SS, Zhao VM, Hebbar G, Ziegler TR: Amino acid composition in parenteral nutrition: what is the evidence? Curr Opin Clin Nutr Metab Care 2011; 14:75-82

6. Guadagni M, Biolo G: Effects of inflammation and/or inactivity on the need for dietary protein. Curr Opin Clin Nutr Metab Care 2009; 12:617-22

7. Mehta NM, Compher C; A.S.P.E.N. Board of Directors: A.S.P.E.N. Clinical Guidelines: nutrition support of the critically ill child. JPEN J Parenter Enteral Nutr 2009; 33:260-276

8. Klaude M, Mori M, Tjäder I, Gustafsson T, Wernerman J, Rooyackers O: Protein metabolism and gene expression in skeletal muscle of ICU patients with sepsis. Clin Sci 2012; 122:133-142

9. Rennie MJ, Bohé J, Wolfe RR: Latency, duration and dose response relationships of amino acid effects on human muscle protein synthesis. J Nutr 2002; 132:3225S-3227S

10. Roth E: Immune and cell modulation by amino acids. Clin Nutr 2007; 26:535-544

11. Garlick PJ: Assessment of the safety of glutamine and other amino acids. J Nutr 2001; 131:2556S2261S 
12. Briassoulis G, Tsorva A, Zavras N, Hatzis T: Influence of an aggressive early enteral nutrition protocol on nitrogen balance in critically ill children. J Nutr Biochem 2002; 13:560-569

13. van Waardenburg DA, de Betue CT, Luiking YC, Engel M, Deutz NE: Plasma arginine and citrulline concentrations in critically ill children: strong relation with inflammation. Am J Clin Nutr 2007; 86:1438-1444

14. van Waardenburg DA, de Betue CT, Goudoever JB, Zimmermann LJ, Joosten KF: Critically ill infants benefit from early administration of protein and energy-enriched formula: a randomized controlled trial. Clin Nutr 2009; 28:249-255

15. Zappitelli M, Juarez M, Castillo L, Coss-Bu J, Goldstein SL: Continuous renal replacement therapy amino acid, trace metal and folate clearance in critically ill children. Intensive Care Med 2009; 35:698-706

16. Vlasselaers D, Milants I, Desmet L, et al: Intensive insulin therapy for patients in paediatric intensive care: a prospective, randomised controlled study. Lancet 2009; 373:547-556

17. Mesotten D, Gielen M, Sterken C, et al: Neurocognitive development of children 4 years after critical illness and treatment with tight glucose control: a randomized controlled trial. JAMA 2012; 308:doi:10.1001/jama.2012.12424

18. Shann F, Henning R, Shekerdemian L (Eds): Paediatric intensive care guidelines. $3^{\text {rd }}$ Edition. Victoria, Collective, 2008

19. Gore DC, Chinkes DL, Hart DW, et al: Hyperglycemia exacerbates muscle protein catabolism in burn-injured patients. Crit Care Med 2002; 30:2438-2442

20. Cynober LA: Plasma amino acid levels with a note on membrane transport: characteristics, regulation, and metabolic significance. Nutrition 2002;18:761-766

21. Langouche L, Vander Perre S, Wouters PJ, D'Hoore A, Hansen TK, Van den Berghe G: Effect of intensive insulin therapy on insulin sensitivity in the critically ill. J Clin Endocrinol Metab 2007; 92:3890-3897

22. Hammarqvist F, Angsten G, Meurling S, Andersson K, Wernerman J: Age-related changes of muscle and plasma amino acids in healthy children. Amino Acids 2010; 39:359-366 
23. Brown TC, Connelly JF, Dunlop ME, McDougall PN, Tibballs J: Fasting plasma glucose in children. Aust Paediatr J 1980; 16:28-29

24. Vesali RF, Klaude M, Rooyackers OE, Tjäder I, Barle H, Wernerman J. Longitudinal pattern of glutamine/glutamate balance across the leg in long-stay intensive care unit patients. Clin Nutr 2002; 21:505-514

25. Powell-Tuck J: Nutritional interventions in critical illness. Proc Nutr Soc 2007; 66:16-24

26. Vanhorebeek I, Van den Berghe G: Hormonal and metabolic strategies to attenuate catabolism in critically ill patients. Curr Opin Pharmacol 2004; 4:621-628

27. Premji SS, Fenton TR, Sauve RS: Higher versus lower protein intake in formula-fed low birth weight infants. Cochrane Database Syst Rev 2006; CD003959

28. Pierro A, Eaton S: Metabolism and nutrition in the surgical neonate. Semin Pediatr Surg 2008; $17: 276-284$

29. Brunton JA, Ball RO, Pencharz PB: Current total parenteral nutrition solutions for the neonate are inadequate. Curr Opin Clin Nutr Metab Care 2000; 3:299-304

30. Kamata S, Imura K, Kawahara H, Kubota A, Okada A: Early postoperative change of plasma levels of amino acids in neonates with perforative peritonitis and its prognostic significance. $J$ Pediatr Surg 1995; 30:559-562

31. Vanhorebeek I, Gunst J, Derde S, et al: Insufficient activation of autophagy allows cellular damage to accumulate in critically ill patients. J Clin Endocrinol Metab 2011; 4:E633-E645

32. Derde S, Vanhorebeek I, Güiza F, et al: Early parenteral nutrition evokes a phenotype of autophagy deficiency in liver and skeletal muscle of critically ill rabbits. Endocrinology 2012, $153: 2267-2276$

33. Eskelinen EL, Saftig P: Autophagy: a lysosomal degradation pathway with a central role in health and disease. Biochim Biophys Acta 2009; 1793:664-673

34. Komatsu M, Ichimura Y: Selective autophagy regulates various cellular functions. Genes Cells 2010; 15:923-933

35. Glick D, Barth S, Macleod KF: Autophagy: cellular and molecular mechanisms. J Pathol 2010; 221:3-12 
36. Meijer AJ: Amino acid regulation of autophagosome formation. Methods Mol Biol 2008; 445:89109

37. Derde S, Vanhorebeek I, Ververs E-J, et al: Increasing intravenous glucose load in the presence of normoglycemia: effect on outcome and metabolism in critically ill rabbits. Crit Care Med 2010; 38:602-611

38. Biolo G, De Cicco M, Lorenzon S, et al: Treating hyperglycemia improves skeletal muscle protein metabolism in cancer patients after major surgery. Crit Care Med 2008; 36:1768-1775

39. Gore DC, Wolf SE, Sanford AP, et al: Extremity hyperinsulinemia stimulates muscle protein synthesis in severely injured patients. Am J Physiol Endocrinol Metab 2004; 286:E529-E534

40. Agus MS, Steil GM, Wypij D, et al: Tight glycemic control versus standard care after pediatric cardiac surgery. N Engl J Med 2012; 367:1208-1219

41. Alsweiler JM, Harding JE, Bloomfield FH: Tight glycemic control with insulin in hyperglycemic preterm babies: a randomized controlled trial. Pediatrics 2012; 129:639-647

42. Lepage N, McDonald N, Dallaire L, Lambert M: Age-specific distribution of plasma amino acid concentrations in a healthy pediatric population. Clin Chem 1997; 43:2397-2402

43. Casaer MP, Mesotten D, Hermans G, et al: Early versus late parenteral nutrition in critically ill adults. $N$ Engl J Med 2011; 365:506-517 


\section{FIGURE LEGENDS}

\section{Figure 1. CONSORT diagram}

The diagram shows how the 100 selected cardiac surgery patients are distributed in the general patient population included in the large randomized controlled study. To address the impact of at least a few days of critical illness and of the intervention, we confined our analyses to patients in ICU for at least 3 days (median ICU stay in the parent study), thus leaving available 163 and 127 patients in the CIT and IIT groups, respectively. To assess the impact of more prolonged critical illness, we studied a second time point, a priori set at 7 days in ICU. Of the 163 CIT patients remaining available for selection, 100 patients had an ICU stay between 3 and 6 days (61\%) and 63 had an ICU stay of at least 7 days (39\%). Thus, we proportionally selected 30 patients (60\%) with an ICU stay between 3 and 6 days and 20 patients (40\%) with an ICU stay of at least 7 days. In view of the higher proportion of infants among the patients remaining available, we withheld more infants (30 patients) than children (20 patients), randomly selected among the groups of interest. We maintained the same proportions with regard to ICU stay and age group to randomly select 50 patients from the IIT group.

The selection included 10 non-survivors, 40 children $>1$ year old and 60 infants of which 15 neonates, for whom the distribution according to randomization and ICU length of stay is indicated. This is shown as the number of non-survivors, children, infants and neonates withheld in the selection, relative to the total number of non-survivors, children, infants and neonates in each final arm of the diagram.

\section{Figure 2. Natural time course of amino acid concentrations during intensive care}

Differences in amino acid concentrations over time were analyzed by repeated measures ANOVA. The line plots (means \pm standard error of the mean) represent the changes in single amino acid concentrations, sum of branched chain amino acids (BCAA), sum of essential amino acids (EAA) and sum of all measured amino acids (total AA) on day 3 (d3) and day 7 (d7) versus the admission (adm) values. The means (circles, triangles) and standard error of the means (whiskers) are shown for 40 patients with an ICU stay of at least 7 days (black circles) and 60 patients with an ICU stay of 
minimum 3 but less than 7 days (grey triangles). $\mathrm{P}^{7 \mathrm{~d}}=$ within-subjects main effect of time for patients with an ICU stay of at least 7 days, $\mathrm{P}^{<7 \mathrm{~d}}=$ within-subjects main effect of time for patients with an ICU stay of minimum 3 but less than 7 days.

\section{Figure 3. The effect of survival or death on amino acid concentrations during intensive care}

Differences in amino acid concentrations between survivors and non-survivors and the evolution over time were analyzed by repeated measures ANOVA. The line plots (means \pm standard error of the mean) represent the changes in single amino acid concentrations, sum of branched chain amino acids (BCAA), sum of essential amino acids (EAA) and sum of all measured amino acids (total AA) on day 3 (d3) and day 7 (d7) versus the admission (adm) values. The means (circles, triangles) and standard error of the means (whiskers) are shown for 40 patients with an ICU stay of at least 7 days (31 ICU survivors, open black circles; 9 ICU death, open grey triangles). Since only one of the 60 patients with an ICU stay of minimum 3 but less than 7 days died in ICU, we did not include these patients in the graphs. $\mathrm{P}^{7 \mathrm{~d}}=p$ for patients with an ICU stay of at least 7 days; $\mathrm{M}=$ between-subjects main effect of mortality; $\mathrm{T}$ = within-subjects main effect of time; $\mathrm{I}$ = between-subjects by withinsubjects interaction of mortality by time.

Figure 4. The effect of intensive insulin therapy on amino acid concentrations during intensive care

Differences in amino acid concentrations between patients with intensive insulin therapy (IIT) and conventional therapy (CIT) and the evolution over time were analyzed by repeated measures ANOVA. The line plots (means \pm standard error of the mean) represent the changes in single amino acid concentrations, sum of branched chain amino acids (BCAA), sum of essential amino acids (EAA) and sum of all measured amino acids (total AA) on day 3 (d3) and day 7 (d7) versus the admission (adm) values. The means (circles, triangles) and standard error of the means (whiskers) are shown for 40 patients with an ICU stay of at least 7 days (20 CIT, black circles; 20 ITT, grey circles) and 60 patients with an ICU stay of minimum 3 but less than 7 days (30 CIT, black triangles; 30 IIT, grey triangles). $\mathrm{P}^{7 \mathrm{~d}}=p$ for patients with an ICU stay of at least 7 days; $\mathrm{P}^{<\mathrm{d}}=p$ for patients with an ICU 
stay of minimum 3 but less than 7 days; $\mathrm{R}$ = between-subjects main effect of therapy (randomization); $\mathrm{T}$ = within-subjects main effect of time; $\mathrm{I}$ = between-subjects by within-subjects interaction of therapy by time.

Figure 5. The effect of age on amino acid concentrations during intensive care: neonates versus older infants and children

Differences in amino acid concentrations between neonates and the group of older infants and children and the evolution over time were analyzed by repeated measures ANOVA. The line plots (means \pm standard error of the mean) represent the changes in single amino acid concentrations, sum of branched chain amino acids (BCAA), sum of essential amino acids (EAA) and sum of all amino acids (total AA) on day 3 (d3) and day 7 (d7) versus the admission (adm) values. The means (circles, triangles) and standard error of the means (whiskers) are shown for 40 patients with an ICU stay of at least 7 days (30 no neonates, black circles; 10 neonates, grey circles) and 60 patients with an ICU stay of minimum 3 but less than 7 days (55 no neonates, black triangles; 5 neonates, grey triangles). $\mathrm{P}^{7 \mathrm{~d}}=p$ for patients with an ICU stay of at least 7 days; $\mathrm{P}^{<7 \mathrm{~d}}=p$ for patients with an ICU stay of minimum 3 but less than 7 days; $\mathrm{N}$ = between-subjects main effect of age (yes or no neonate); $\mathrm{T}$ = within-subjects main effect of time; I = between-subjects by within-subjects interaction of age by time. 
Table 1: Baseline characteristics, treatments in ICU and outcome of the patients

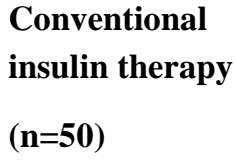

Baseline characteristics

Infant (age $<1$ year) (no., \%)

Neonate (age $<4$ weeks) (no., \%)

Weight (kg) (median - IQR)

$\mathrm{BMI}($ mean $\pm \mathrm{SD})$

Gender (no., \% male)

Pre-randomization syndrome (no., \%)

RACHS score (median - IQR)

Mechanical ventilation (no., \%)

ECMO or other assist device upon admission (no, \%)

Inotrope score for first $24 \mathrm{hrs}$ (median - IQR)

Inotrope score for first 24 hrs $>2$ (no., \%)

Blood glucose upon admission $(\mathrm{mg} / \mathrm{dL})($ mean $\pm \mathrm{SD})$

PELOD (first 24 h) (median - IQR)

CRP (mg/L) (median - IQR)

\section{ICU length of stay and mortality}

ICU stay (days) (median - IQR)

ICU mortality (no., \%)

Suspected or documented infection (no., \%)

Temperature $\leq 36^{\circ} \mathrm{C}$ or $\geq 38^{\circ} \mathrm{C}$ (no., \%)

Treated with inotropic drugs (no., \%)

Days on inotropic drugs (median - IQR)

Treated with corticosteroids (no., \%)

Days on corticosteroids (median - IQR)

Treated with NMBAs (no., \%)

Days on NMBAs (median - IQR)

Treated with sedatives (no., \%)

Glucose management

Mean morning blood glucose (mg/dL) (mean \pm SD)

Maximal blood glucose (mean \pm SD)

Treated with insulin (no., \%)

Mean daily insulin dose (IU/kg/day) (median - IQR)

Hypoglycemia (no., \%)

Minimal blood glucose (mg/dL) (mean \pm SD)

$30(60.0)$
$8(16.0)$
$6.4(4.2-10$

$6.4(4.2-10.0)$

$14.8 \pm 2.5$

$30(60.0)$

$20(40.0)$

$3(2-3)$

50 (100)

3 (6.0)

2 (1-3)

17 (34.0)

$163.4 \pm 67.1$

12 (11-12)

23.8 (15.3-51.1)
5 (4-9)

6 (12\%)

28 (56.0)

44 (88.0)

48 (96.0)

4 (3-7)

15 (30.0)

0 (0-1)

20 (40.0)

0 (0-1)

50 (100.0)

$123.0 \pm 21.3$

$305.1 \pm 186.5$

24 (48.0)

$0.00(0.00-0.59)$

1 (2.0)

$80.3 \pm 20.0$

30 (60.0)

$7(14.0)$

$>0.9$

5.7 (3.9-12.0)

0.8

$14.8 \pm 2.3$

0.7

$30(60.0)$

21 (42.0)

3 (2-3)

50 (100)

3 (6.0)

2 (1-3)

13 (26)

$161.7 \pm 77.5$

12 (11-12)

22.8 (14.8-32.7)

$>0.9$

$>0.9$

0.8

0.7

$>0.9$

$>0.9$

0.2

0.4

0.9

0.5

0.4

5 (4-8)

4 (8\%)

22 (44.0)

45 (90.0)

45 (90.0)

4 (2-7)

$10(20.0)$

$0(0-0)$

19 (38.0)

0 (0-1)

48 (96.0)

$89.9 \pm 16.3$

$252.0 \pm 118.2$

50 (100.0)

1.21 (0.92-1.65)

24 (48)

$42.3 \pm 12.0$
0.9

0.5

0.2

0.7

0.2

0.4

0.2

0.4

0.8

0.9

0.2

$<0.0001$

0.09

$<0.0001$

$<0.0001$

$<0.0001$

$<0.0001$

RACHS: risk adjustment in congenital heart surgery score; ECMO: extracorporeal membrane oxygenation; PELOD: pediatric logistic organ dysfunction score; CRP: C-reactive protein; NMBAs: neuromuscular blocking agents. To convert glucose to mmol/L multiply by 0.05551 . 
Table 2: Amino acid and total caloric intake during intensive care unit stay

\begin{tabular}{|c|c|c|c|c|c|c|c|c|}
\hline $\begin{array}{c}\text { Amino acid } \\
\mathrm{mg} / \mathrm{kg}\end{array}$ & $\begin{array}{l}\text { Day in ICU } \\
\text { Day } 3 \\
\text { Day } 7\end{array}$ & $\begin{array}{c}\text { All data } \\
n=100 \\
n=40\end{array}$ & $\begin{array}{c}\text { Survivors } \\
\mathrm{n}=90 \\
\mathrm{n}=31\end{array}$ & $\begin{array}{c}\text { Non-survivors } \\
\begin{array}{c}n=10 \\
n=9\end{array}\end{array}$ & $\begin{array}{c}\text { Age } \leq \mathbf{4} \text { weeks } \\
\begin{array}{c}\mathrm{n}=15 \\
\mathrm{n}\end{array}=10\end{array}$ & $\begin{array}{c}\text { Age }>4 \text { weeks } \\
n=85 \\
n=30\end{array}$ & $\begin{array}{l}\text { CIT } \\
\mathrm{n}=50 \\
\mathrm{n}=20\end{array}$ & $\begin{array}{l}\text { IIT } \\
\mathrm{n}=50 \\
\mathrm{n}=20\end{array}$ \\
\hline \multirow[t]{2}{*}{ Alanine } & Day 3 & 78 (65-97) & $76(65-97)$ & $86(78-102)$ & $106(88-128)$ & $72(63-91)$ & $81(66-100)$ & $78(65-92)$ \\
\hline & Day 7 & $153(77-205)$ & $152(66-223)$ & $171(127-195)$ & $171(132-181)$ & 136 (59-224) & $137(65-192)$ & $169(87-210)$ \\
\hline \multirow[t]{2}{*}{ Arginine } & Day 3 & $86(71-103)$ & $82(70-103)$ & $91(85-105)$ & $112(91-130)$ & $77(69-98)^{a}$ & $85(70-105)$ & $86(71-101)$ \\
\hline & Day 7 & $107(80-131)$ & $102(79-150)$ & $111(82-127)$ & $112(91-117)$ & $102(71-156)$ & $101(75-128)$ & $120(87-142)$ \\
\hline \multirow[t]{2}{*}{ Asparagine } & Day 3 & $0(0-0)$ & $0(0-0)$ & $0(0-0)$ & $0(0-0)$ & $0(0-0)$ & $0(0-0)$ & $0(0-0)$ \\
\hline & Day 7 & $0(0-0)$ & $0(0-0)$ & $0(0-0)$ & $0(0-0)$ & $0(0-0)$ & $0(0-0)$ & $0(0-0)$ \\
\hline \multirow[t]{2}{*}{ Aspartic acid } & Day 3 & $106(88-125)$ & $103(88-124)$ & $113(85-129)$ & $126(113-148)$ & $98(86-118)$ & $109(87-129)$ & $104(88-122)$ \\
\hline & Day 7 & $91(55-116)$ & $87(51-109)$ & $111(82-127)$ & $112(93-117)$ & $83(48-102)$ & $86(51-106)$ & $97(60-125)$ \\
\hline \multirow[t]{2}{*}{ Cysteine } & Day 3 & $34(30-43)$ & $34(30-43)$ & $37(29-41)$ & $43(32-51)$ & $33(29-41)$ & $35(30-45)$ & $34(29-42)$ \\
\hline & Day 7 & $26(12-31)$ & $25(11-32)$ & $27(20-31)$ & $28(23-31)$ & $21(10-31)$ & $23(13-32)$ & 27 (12-31) \\
\hline \multirow[t]{2}{*}{ Glutamine } & Day 3 & $0(0-0)$ & $0(0-0)$ & $0(0-0)$ & $0(0-0)$ & $0(0-0)$ & $0(0-0)$ & $0(0-0)$ \\
\hline & Day 7 & $0(0-0)$ & $0(0-0)$ & $0(0-0)$ & $0(0-0)$ & $0(0-0)$ & $0(0-0)$ & $0(0-0)$ \\
\hline \multirow[t]{2}{*}{ Glutamate } & Day 3 & $223(192-265)$ & $216(192-267)$ & $236(187-262)$ & 276 (219-325) & $214(189-257)^{a}$ & 224 (190-267) & $216(192-258)$ \\
\hline & Day 7 & $170(103-212)$ & $169(98-205)$ & $193(143-220)$ & $193(161-213)$ & 159 (84-212) & 166 (98-193) & $173(103-221)$ \\
\hline \multirow[t]{2}{*}{ Glycine } & Day 3 & $54(45-65)$ & $53(45-65)$ & $58(44-66)$ & $67(58-82)$ & $50(44-63)$ & $56(44-66)$ & $54(45-63)$ \\
\hline & Day 7 & $60(46-8$ & $60(50-110)$ & $57(42-65)$ & $58(48-60)$ & $63(45-110)$ & $57(42-75)$ & $62(53-95)$ \\
\hline \multirow[t]{2}{*}{ Histidine } & Day 3 & $60(51-74)$ & $58(51-75)$ & $65(50-70)$ & 76 (64-94) & $57(50-69)$ & $60(50-75)$ & $60(52-72)$ \\
\hline & Day 7 & $61(47-84)$ & $62(51-94)$ & $57(42-65)$ & $59(48-63)$ & $65(47-94)$ & 57 (45-74) & 65 (52-94) \\
\hline \multirow[t]{2}{*}{ Isoleucine } & Day 3 & 97 (83-122) & 94 (84-124) & $102(81-113)$ & $124(102-152)$ & $93(82-113)$ & $97(82-125)$ & 97 (84-118) \\
\hline & Day 7 & 87 (72-102) & 88 (75-114) & $84(62-96)$ & $87(70-96)$ & 87 (73-116) & $81(67-100)$ & $94(77-103)$ \\
\hline \multirow[t]{2}{*}{ Leucine } & Day 3 & $138(115-172)$ & $137(114-172)$ & $148(138-168)$ & $180(147-212)$ & $127(111-160)^{a}$ & $143(116-174)$ & $137(114-162)$ \\
\hline & Day 7 & $161(110-210)$ & 147 (105-205) & $190(141-216)$ & $191(147-210)$ & 139 (100-209) & $153(107-204)$ & 169 (115-213) \\
\hline \multirow[t]{2}{*}{ Lysine } & Day 3 & $101(85-126)$ & $101(84-127)$ & $112(101-124)$ & $132(114-161)$ & $94(82-118)$ & $107(85-128)$ & $101(84-120)$ \\
\hline & Day 7 & $143(90-173)$ & 139 (79-171) & $152(113-173)$ & $152(117-168)$ & $138(73-176)$ & $131(84-163)$ & 159 (98-173) \\
\hline \multirow[t]{2}{*}{ Methionine } & Day 3 & $46(40-58)$ & $46(40-59)$ & $50(39-55)$ & $60(50-74)$ & $45(40-55)$ & $46(39-60)$ & $47(41-57)$ \\
\hline & Day 7 & 40 (34-71) & 45 (36-77) & $35(26-40)$ & $36(30-40)$ & 44 (36-77) & 39 (28-66) & 40 (38-77) \\
\hline \multirow[t]{2}{*}{ Phenylalanine } & Day 3 & $132(115-168)$ & $132(116-168)$ & $144(112-160)$ & $175(144-215)$ & $130(113-158)^{a}$ & $132(110-169)$ & $137(117-166)$ \\
\hline & Day 7 & 85 (66-139) & 109 (70-148) & $73(54-83) \quad a$ & $75(61-83)$ & 108 (67-145) & 78 (63-124) & 94 (76-142) \\
\hline \multirow[t]{2}{*}{ Proline } & Day 3 & $194(170-246)$ & $194(170-247)$ & $212(168-235)$ & $248(212-292)$ & $191(169-234)^{a}$ & $194(168-253)$ & $202(173-244)$ \\
\hline & Day 7 & $152(102-178)$ & 153 (101-188) & $152(113-173)$ & $157(127-168)$ & 146 (96-189) & $143(100-184)$ & 156 (120-175) \\
\hline
\end{tabular}




\begin{tabular}{|c|c|c|c|c|c|c|c|c|c|}
\hline $\begin{array}{c}\text { Amino acid } \\
\mathrm{mg} / \mathrm{kg}\end{array}$ & $\begin{array}{l}\text { Day in ICU } \\
\text { Day } 3 \\
\text { Day } 7\end{array}$ & $\begin{array}{c}\text { All data } \\
n=100 \\
n=40\end{array}$ & $\begin{array}{c}\text { Survivors } \\
n=90 \\
n=31\end{array}$ & $\begin{array}{c}\text { Non-survivors } \\
\qquad \begin{array}{c}n=10 \\
n=9\end{array}\end{array}$ & $\begin{array}{c}\text { Age } \leq \mathbf{4} \text { weeks } \\
n=15 \\
n=10\end{array}$ & \multicolumn{2}{|c|}{$\begin{array}{c}\text { Age }>4 \text { weeks } \\
n=85 \\
n=30\end{array}$} & $\begin{array}{l}\text { CIT } \\
n=50 \\
n=20\end{array}$ & $\begin{array}{l}\mathbf{I I T} \\
n=50 \\
n=20\end{array}$ \\
\hline \multirow[t]{2}{*}{ Serine } & Day 3 & 180 (156-225) & $180(157-227)$ & $196(153-218)$ & $230(170-271)$ & \multicolumn{2}{|l|}{$177(153-215)^{a}$} & 180 (145-229) & $180(160-215)$ \\
\hline & Day 7 & $104(79-136)$ & 105 (79-154) & $103(76-118)$ & 106 (86-115) & \multicolumn{2}{|l|}{$100(68-146)$} & $98(68-137)$ & $111(84-136)$ \\
\hline \multirow[t]{2}{*}{ Taurine } & Day 3 & $0(0-0)$ & $0(0-0)$ & $0(0-0)$ & $0(0-0)$ & $0(0-0)$ & \multirow[b]{2}{*}{$a$} & $0(0-0)$ & $0(0-0)$ \\
\hline & Day 7 & $0(0-7)$ & $0(0-2)$ & $8(6-9)$ & $8(6-9)$ & $0(0-1)$ & & $0(0-7)$ & $0(0-8)$ \\
\hline \multirow[t]{2}{*}{ Threonine } & Day 3 & 78 (65-97) & 75 (64-97) & $83(75-95)$ & $102(83-117)$ & $72(63-90)$ & \multirow[t]{2}{*}{$a$} & 79 (66-98) & $78(65-92)$ \\
\hline & Day 7 & $94(66-111)$ & $90(61-111)$ & 98 (72-113) & $98(82-108)$ & 88 (56-113) & & $83(61-112)$ & $100(72-111)$ \\
\hline \multirow[t]{2}{*}{ Tryptophan } & Day 3 & $26(22-32)$ & $25(21-32)$ & $29(26-32)$ & $34(29-41)$ & $24(21-30)$ & \multirow[t]{2}{*}{$a$} & 27 (22-33) & $26(22-31)$ \\
\hline & Day 7 & $34(23-40)$ & $34(21-39)$ & 38 (28-43) & $38(29-41)$ & 33 (20-39) & & $30(22-38)$ & $35(24-42)$ \\
\hline \multirow[t]{2}{*}{ Tyrosine } & Day 3 & $13(11-16)$ & $13(11-16)$ & $14(10-16)$ & $15(13-18)$ & $12(11-16)$ & & $14(11-17)$ & $12(11-15)$ \\
\hline & Day 7 & $12(5-16)$ & $12(5-17)$ & $14(10-15)$ & $14(11-15)$ & $10(5-16)$ & & $12(8-16)$ & $13(5-16)$ \\
\hline \multirow[t]{2}{*}{ Valine } & Day 3 & $108(92-135)$ & 107 (92-137) & $113(89-125)$ & 137 (113-168) & $102(90-124)$ & \multirow[t]{2}{*}{$a$} & 108 (91-137) & 107 (93-130) \\
\hline & Day 7 & $102(81-125)$ & $102(85-138)$ & $98(72-111)$ & $101(82-110)$ & $102(81-141)$ & & $98(71-116)$ & 109 (92-128) \\
\hline \multirow[t]{2}{*}{ Total $\mathrm{AA}^{b}$} & Day 3 & $1.8(1.5-2.2)$ & $1.8(1.5-2.2)$ & $1.9(1.5-2.0)$ & $2.2(1.9-2.7)$ & $1.7(1.5-2.0)$ & \multirow[t]{2}{*}{$a$} & $1.8(1.5-2.3)$ & $1.8(1.5-2.1)$ \\
\hline & Day 7 & $1.8(1.4-2.0)$ & $1.8(1.4-2.2)$ & $1.8(1.3-2.0)$ & $1.8(1.5-2.0)$ & 1.7 (1.3-2.3) & & $1.6(1.3-2.1)$ & $2.0(1.7-2.0)$ \\
\hline \multirow[t]{2}{*}{ Total calories $^{c}$} & Day 3 & $40(32-51)$ & $39(32-51)$ & $43(38-49)$ & $49(43-57)$ & $38(30-48)$ & \multirow{2}{*}{$\begin{array}{l}a \\
a\end{array}$} & $42(33-50)$ & $38(31-51)$ \\
\hline & Day 7 & 70 (53-77) & $69(46-78)$ & $70(61-77)$ & 75 (70-79) & $65(38-76)$ & & $68(54-75)$ & 72 (48-78) \\
\hline
\end{tabular}

CIT: conventional insulin therapy, IIT: intensive insulin therapy, total AA: total amino acid intake. ${ }^{a} p \leq 0.05$ in unpaired t-test or Mann-Whitney $\mathrm{U}$ on the respective day for survivors versus non-survivors, neonates versus children older than 4 weeks, or CIT versus IIT. ${ }^{b}$ Total protein intake in g/kg. Amino acidcontaining formulations for parenteral administration included Vamin18, Vamin-glucose and Vaminolact (administered to 1\%, 87\% and 4\% of the patients on day 3 and to 25\%, 33\% and 38\% on day 7). Enteral amino acids were provided via the patient's home milk formula, including breast milk, Aptamil 1, Nan 1, Nan 2, Nutrilon 1, Nutrilon 2, Nutrilon 3, Nutrilon premium, Nutrilon soy, Neocate, Nutramigen, Omneo 2 and Pediasure. ${ }^{c}$ Total caloric intake in kcal/kg; combination of enteral and parenteral nutrition; on day 3 and day 7 at least partial enteral nutrition was tolerated in $28 \%$ and $38 \%$ of the patients, respectively. In most of the patients, the amino acids were administered exclusively by parenteral nutrition. Fourteen (day 3) and 12 (day 7) patients also received amino 
acids via the enteral route but in low amounts as compared to the amino acids administered parenterally. Amino acid intake was missing for 1 patient (survivor, no neonate, CIT patient). 


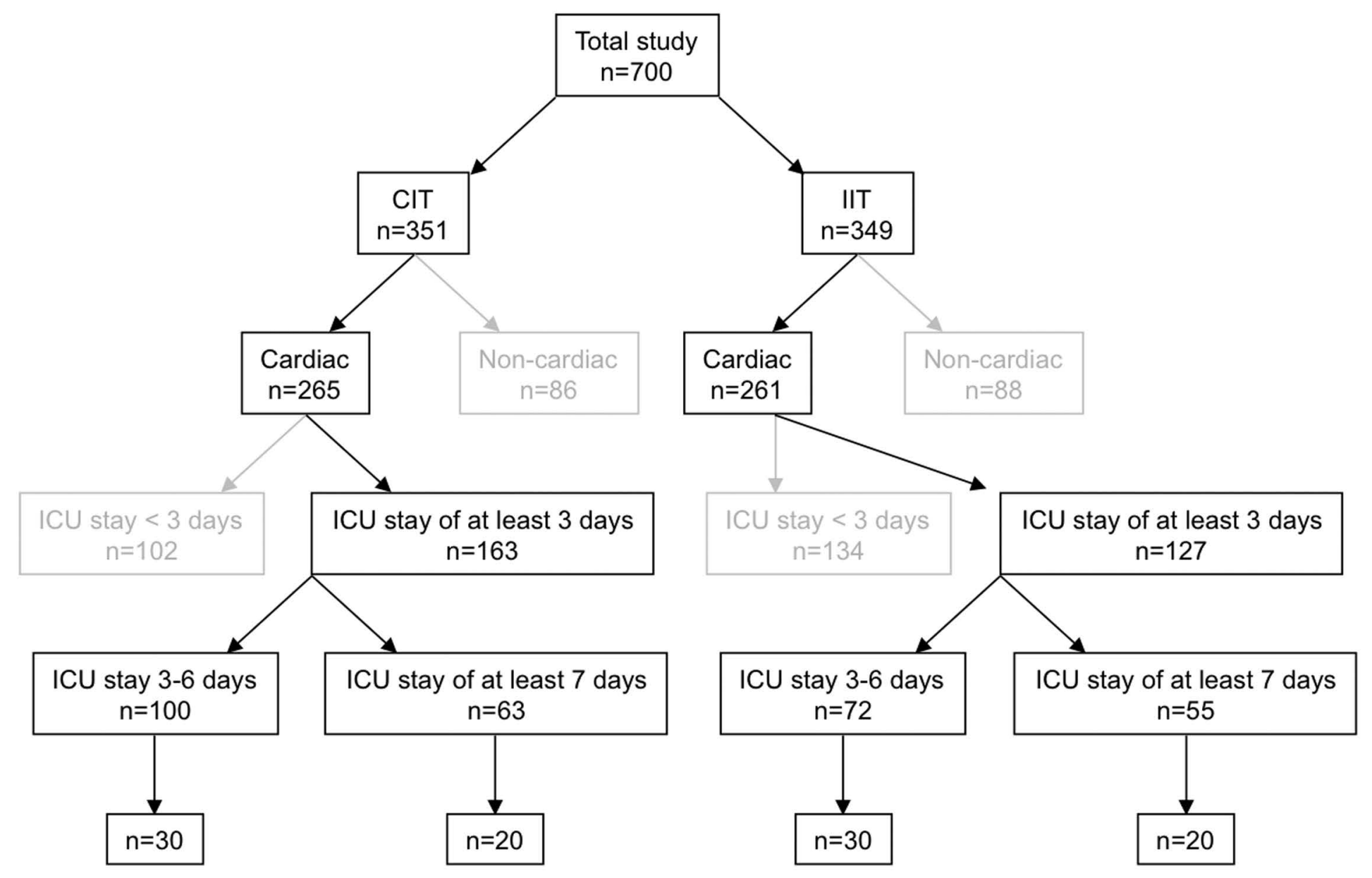

Non-survivors: $n=0$ (of 3) Non-survivors: $n=6$ (of 11)

Children: 13 (of 38) Infants: 17 (of 62)

$\llcorner$ Neonates: $n=2$ (of 14)
Children: 7 (of 14)

Infants: 13 (of 49)

$\llcorner$ Neonates: $n=6$ (of 26)
Non-survivors: $n=1$ (of 3 )

Children: 13 (of 23)

Infants: 17 (of 49)

$\llcorner$ Neonates: $n=3$ (of 13)
Non-survivors: $\mathrm{n}=3$ (of 4 )

Children: 7 (of 10)

Infants: 13 (of 45)

$\llcorner$ Neonates: $n=4$ (of 17 ) 
Total AA

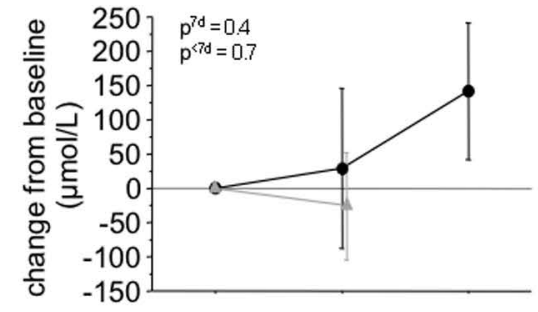

Alanine

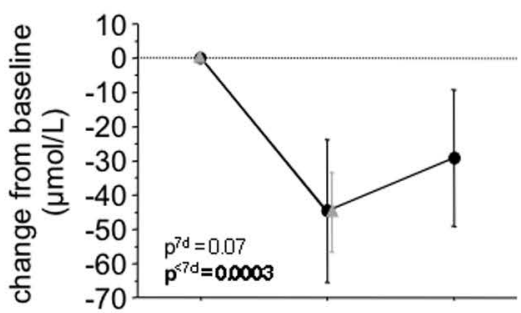

Arginine

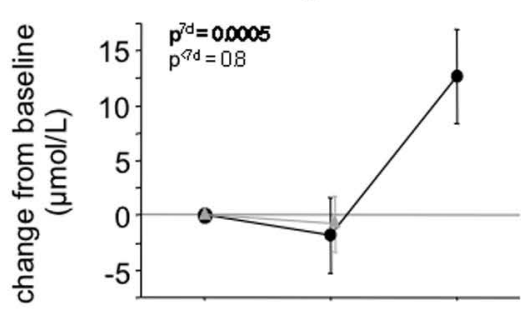

Asparagine

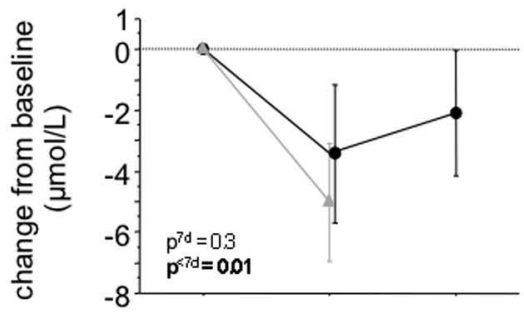

Glutamine

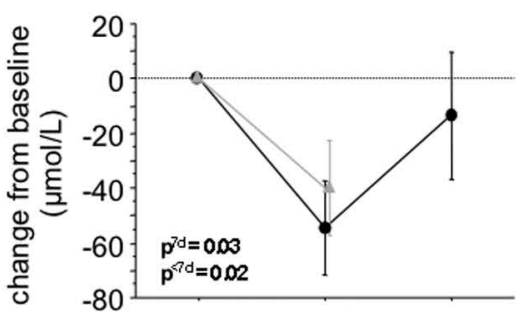

Glutamate

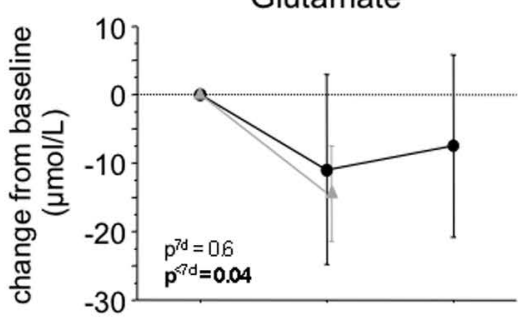

Glycine

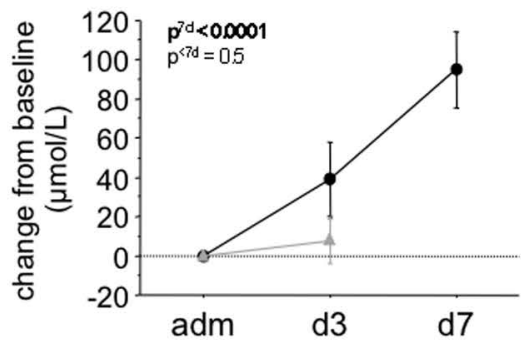

BCAA

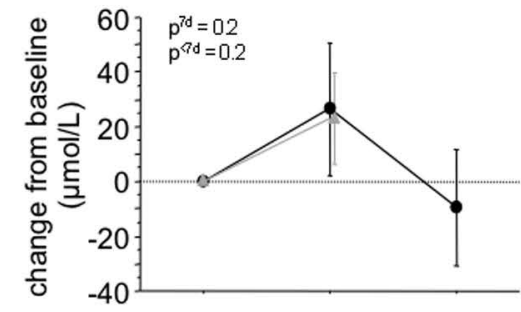

Histidine

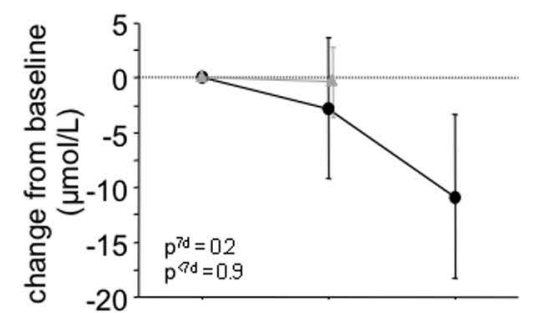

Isoleucine

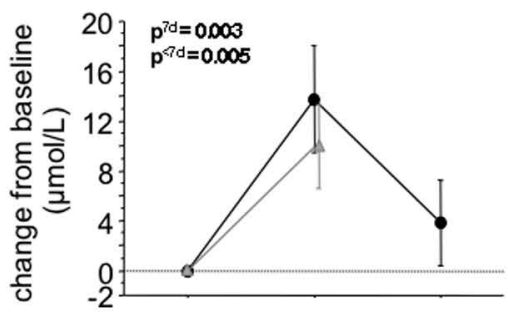

Leucine

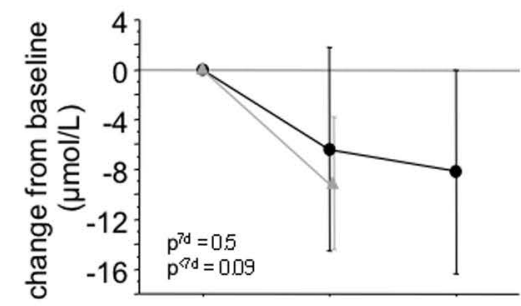

Lysine

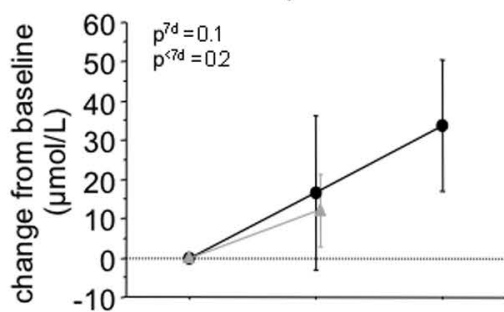

Methionine

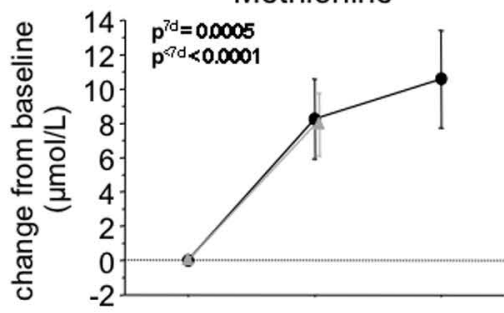

Phenylalanine

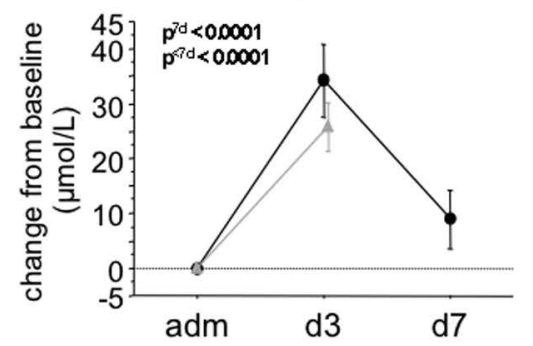

EAA

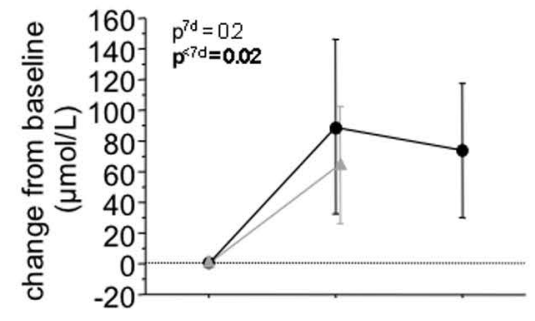

Serine

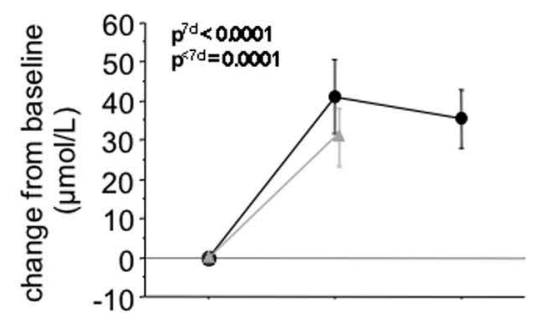

Taurine

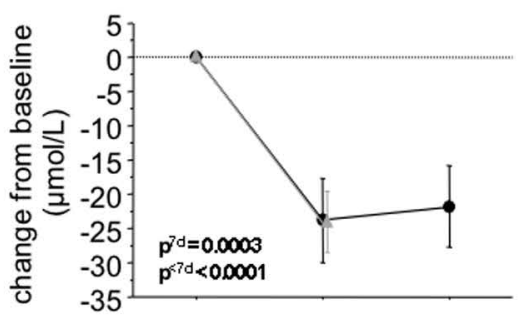

Threonine

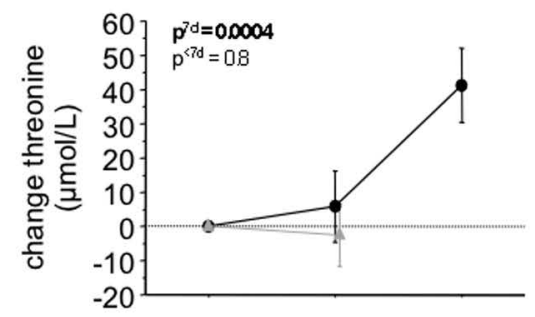

Tryptophan

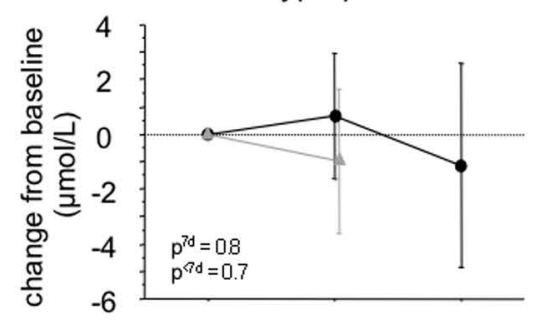

Tyrosine

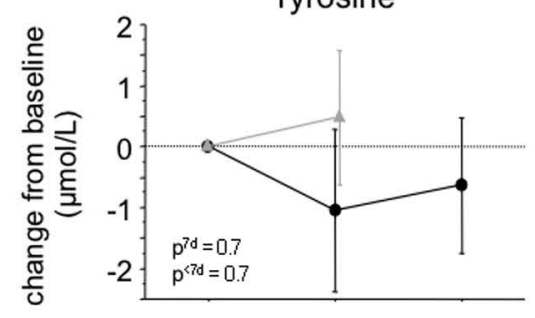

Valine

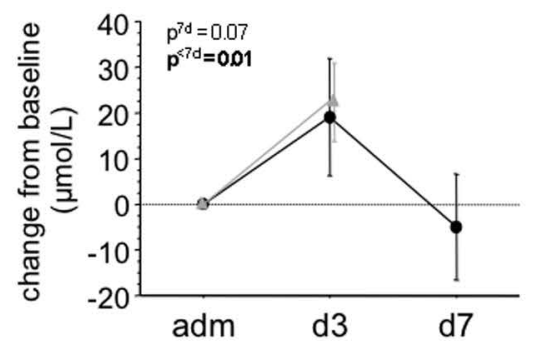


Total AA

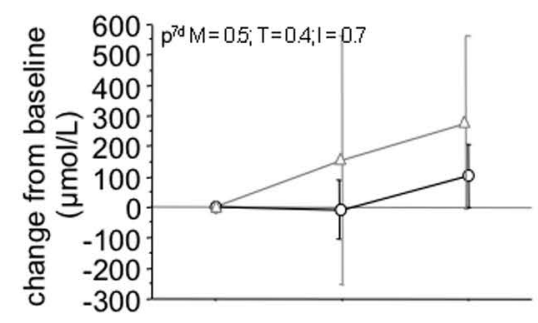

Alanine

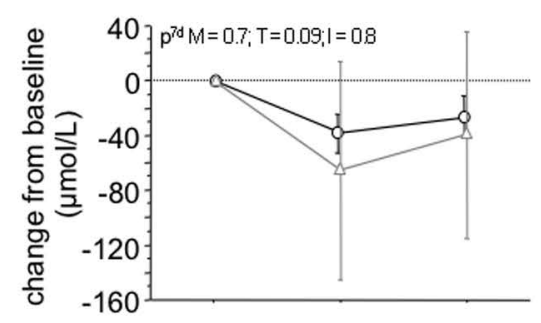

Arginine

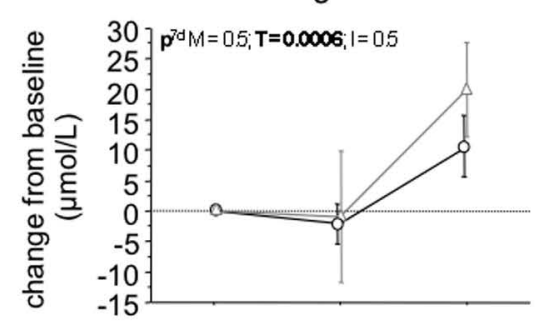

Asparagine

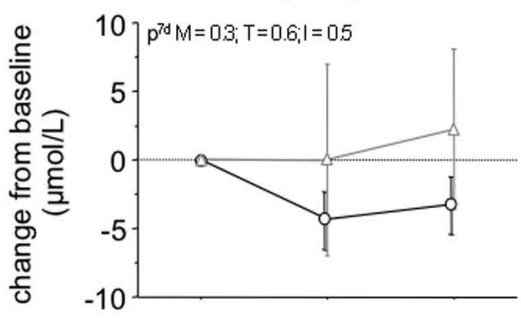

Glutamine

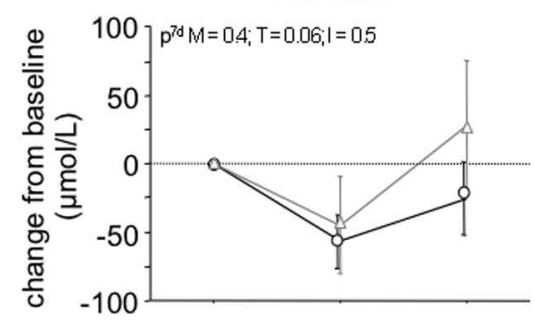

Glutamate

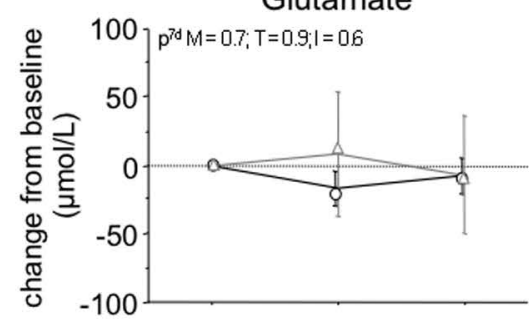

Glycine

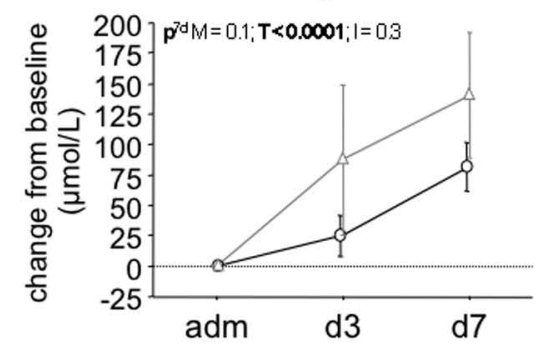

BCAA

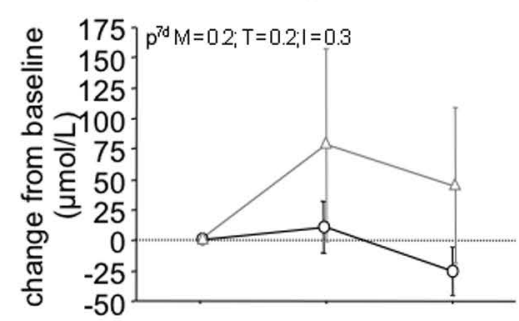

Histidine

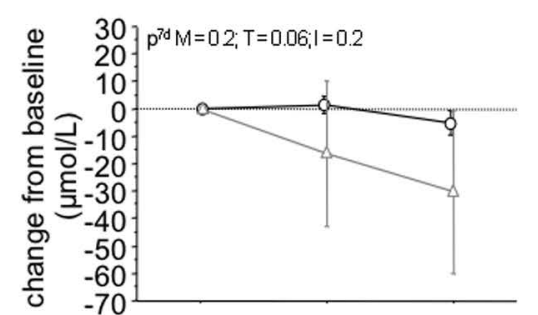

Isoleucine

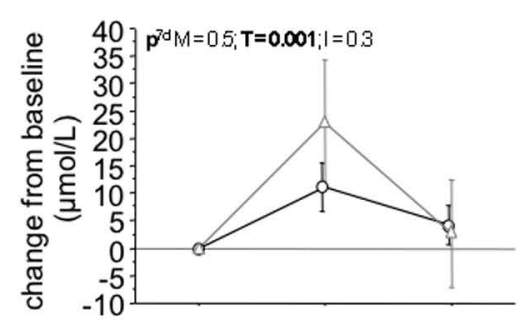

Leucine

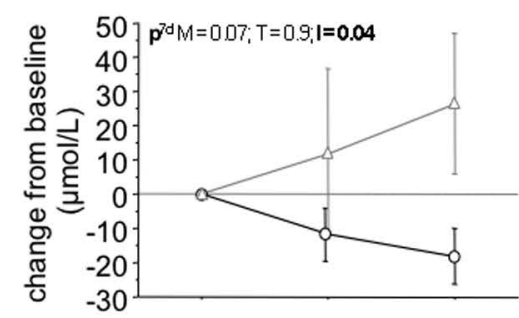

Lysine

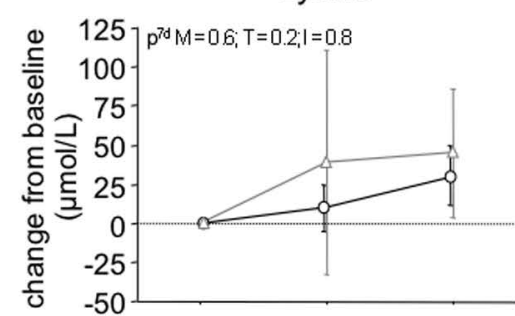

Methionine

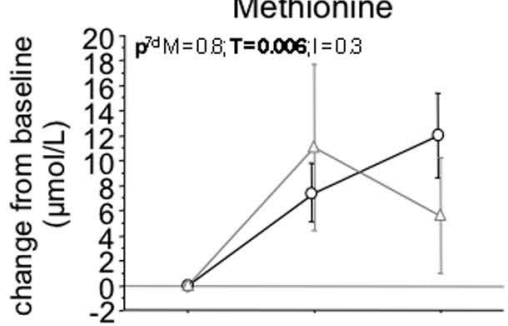

Phenylalanine

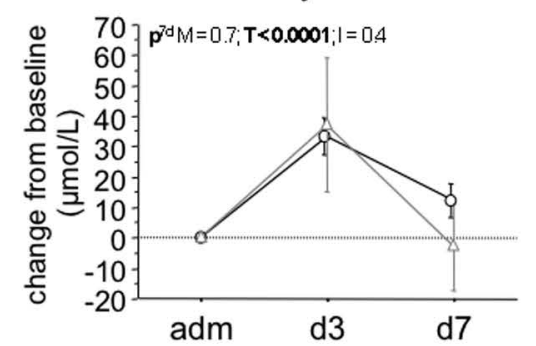

EAA

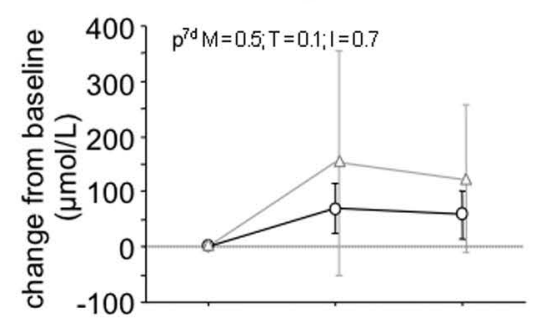

Serine

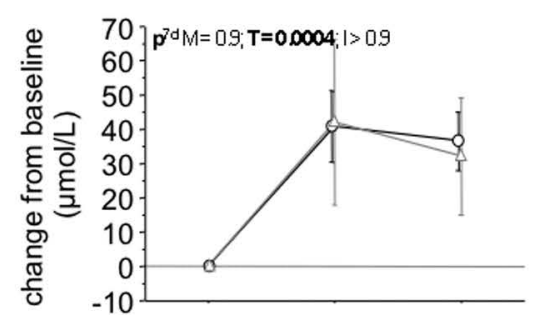

Taurine

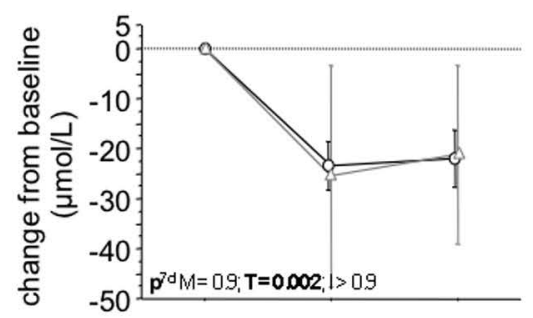

Threonine

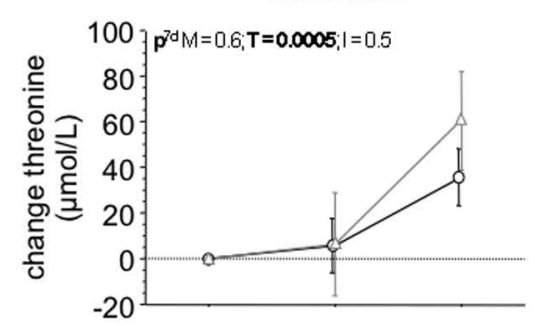

Tryptophan

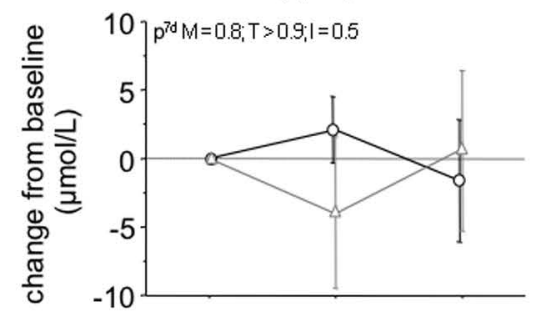

Tyrosine

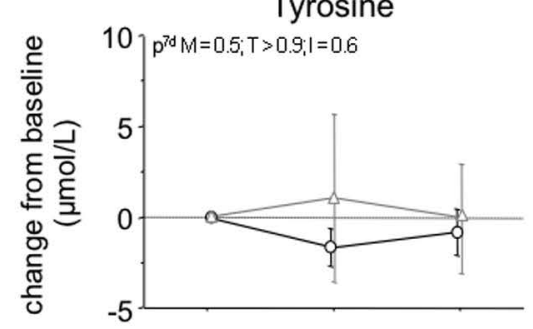

Valine

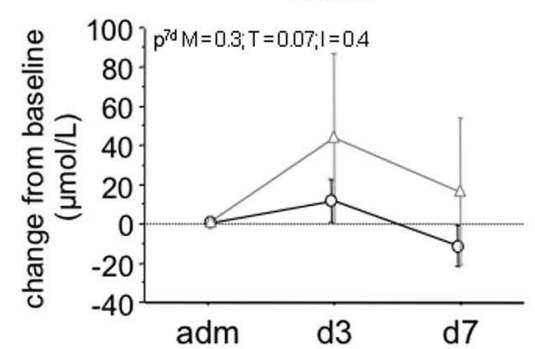


Total AA

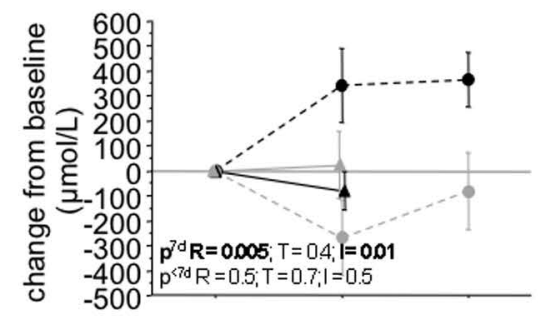

Alanine

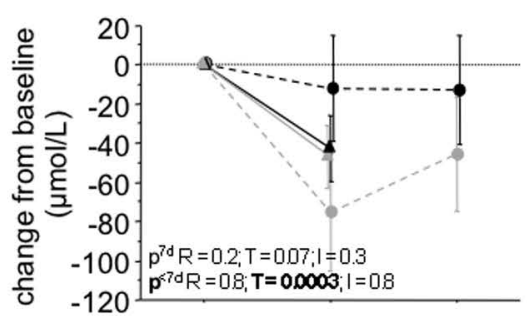

Arginine

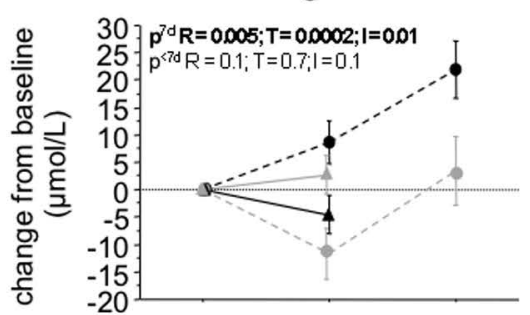

Asparagine

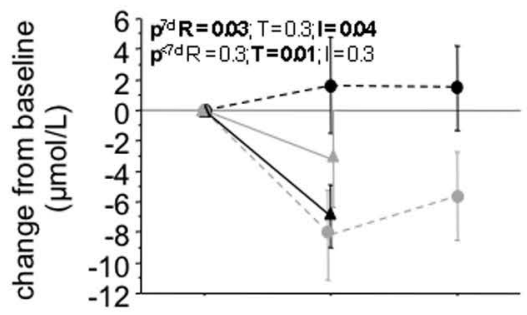

Glutamine

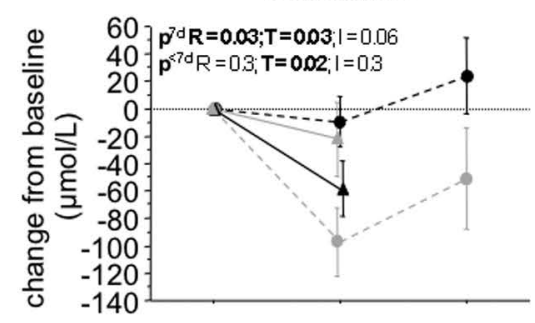

Glutamate

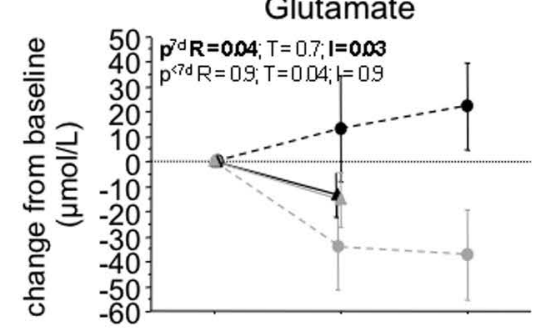

Glycine

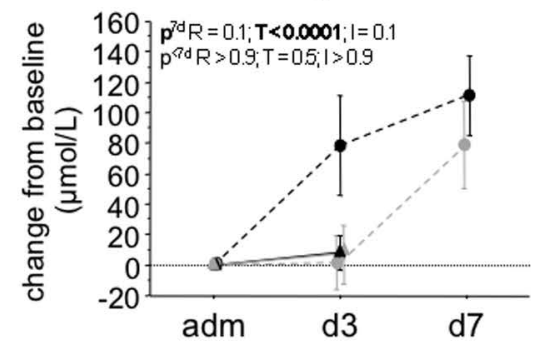

BCAA

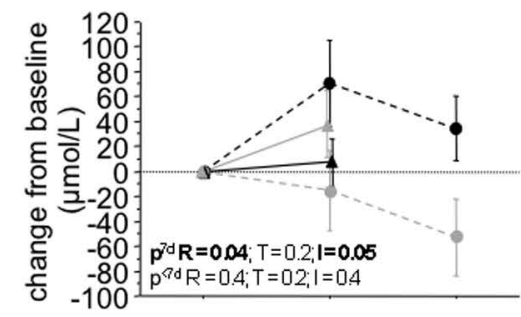

Histidine

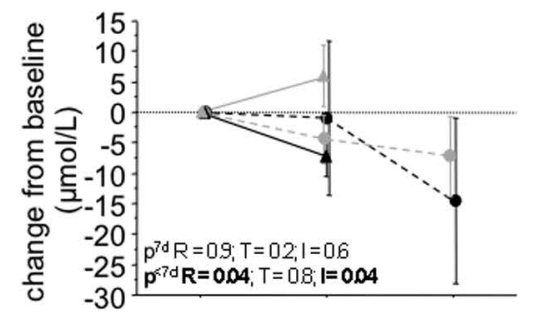

Isoleucine

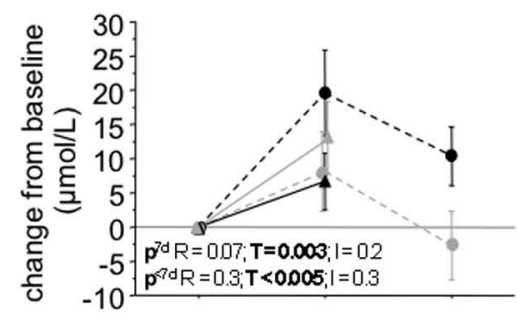

Leucine

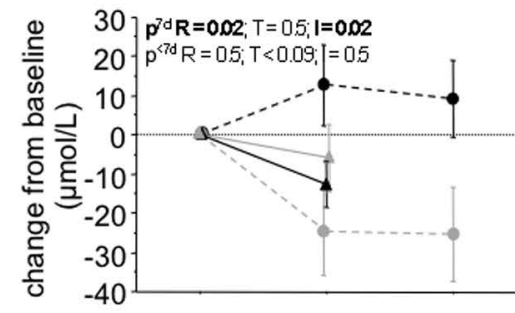

Lysine

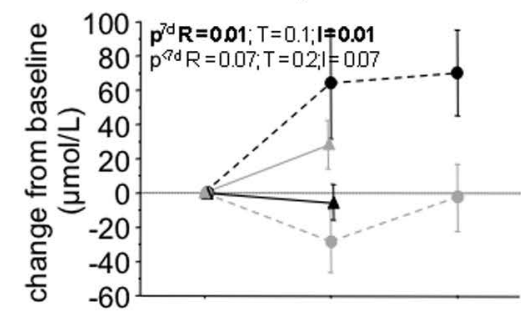

Methionine

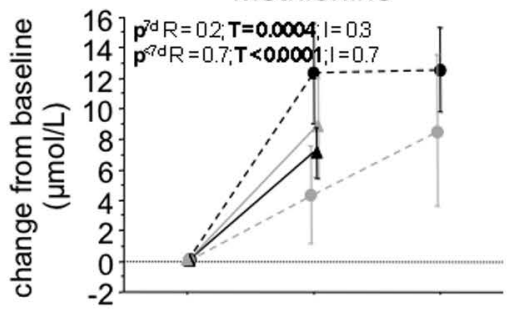

Phenylalanine

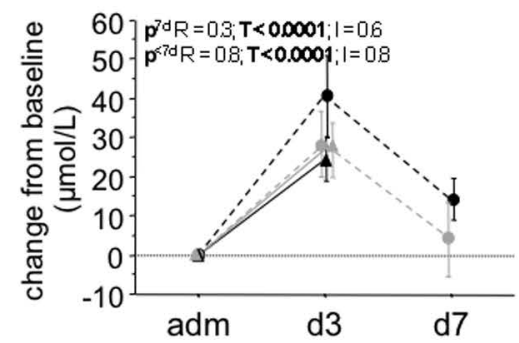

EAA

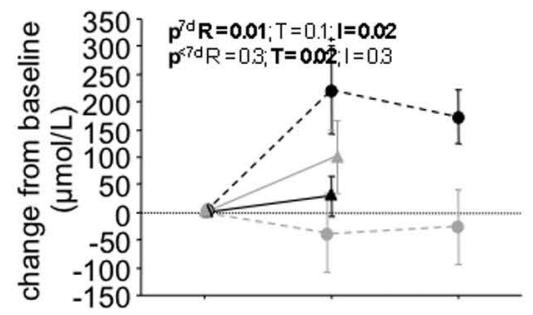

Serine

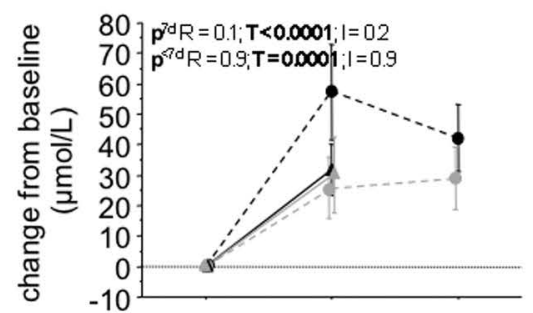

Taurine

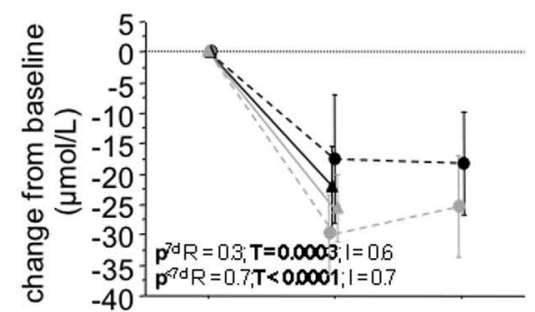

Threonine

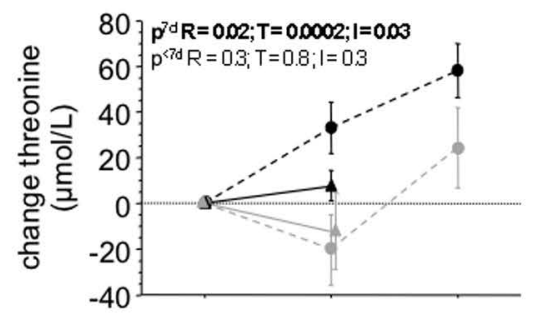

Tryptophan

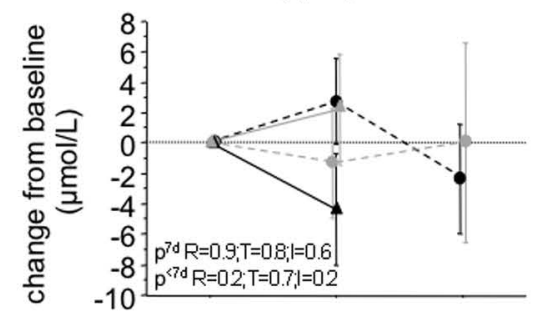

Tyrosine

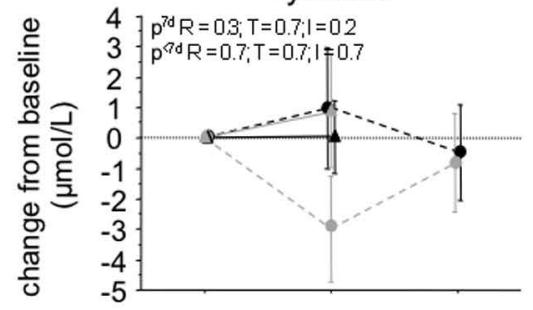

Valine

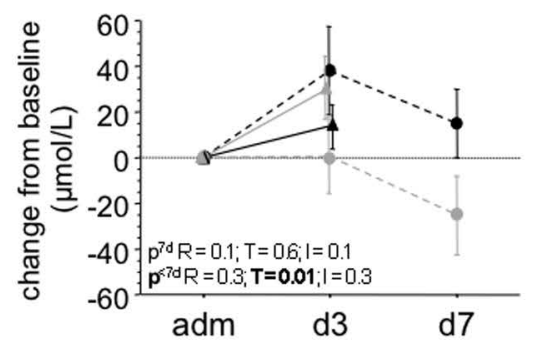


Total AA

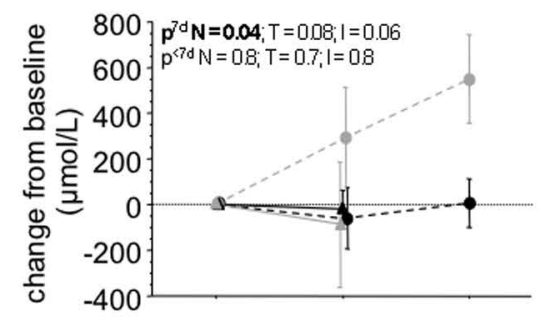

Alanine

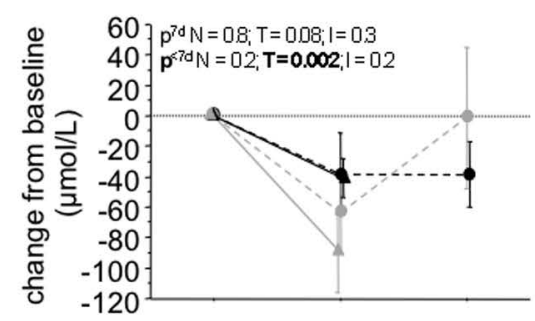

Arginine

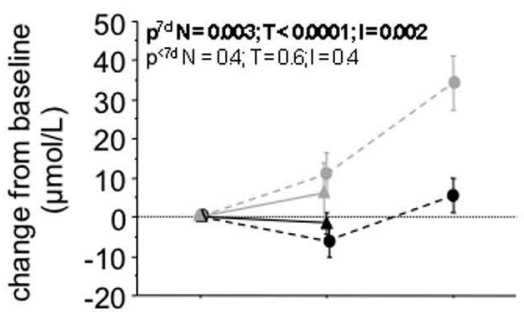

Asparagine

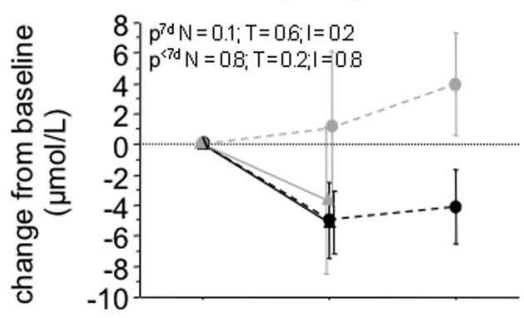

Glutamine

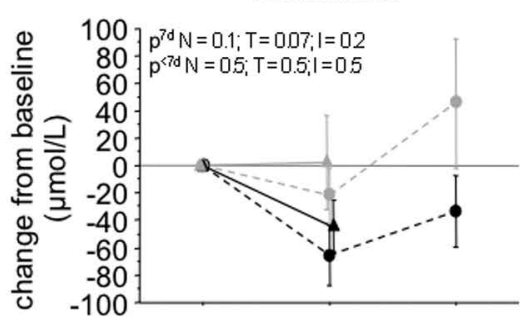

Glutamate

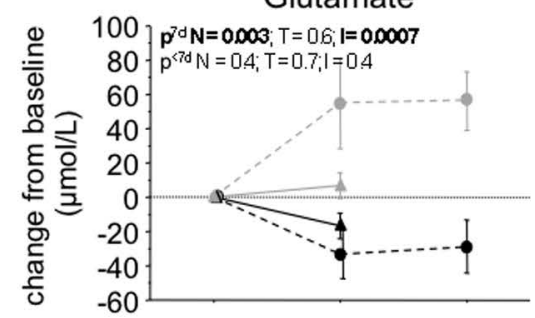

Glycine

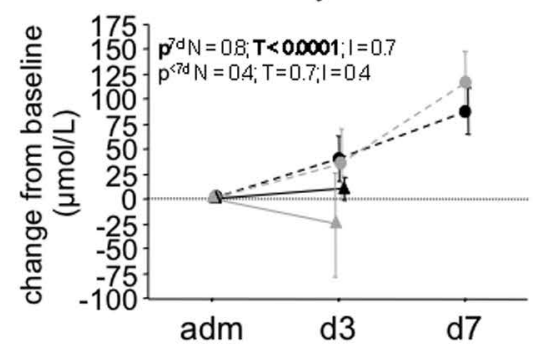

BCAA

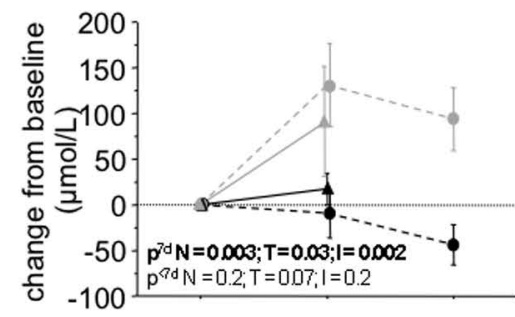

Histidine

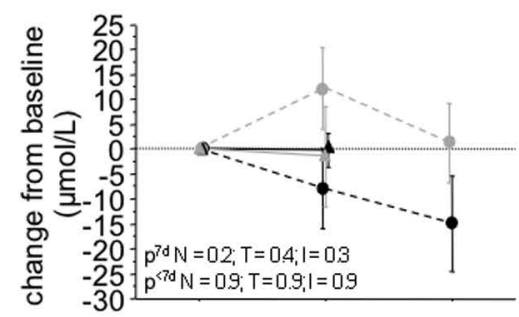

Isoleucine

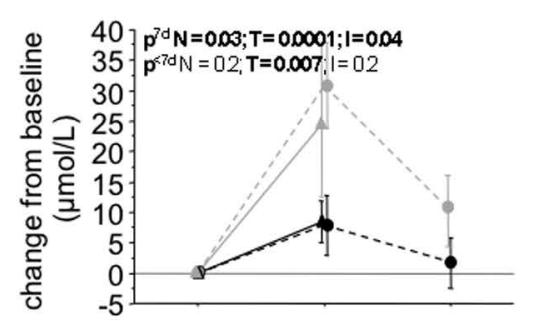

Leucine

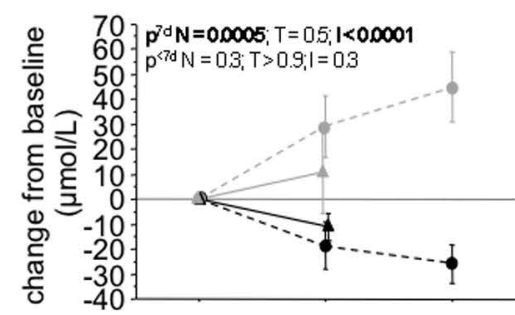

Lysine

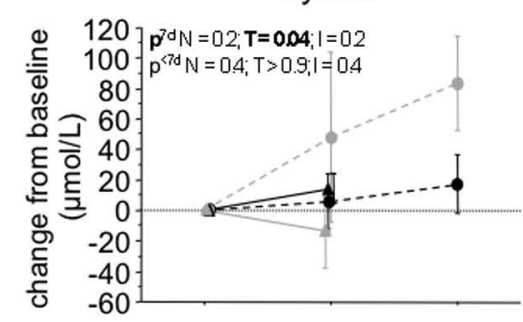

Methionine

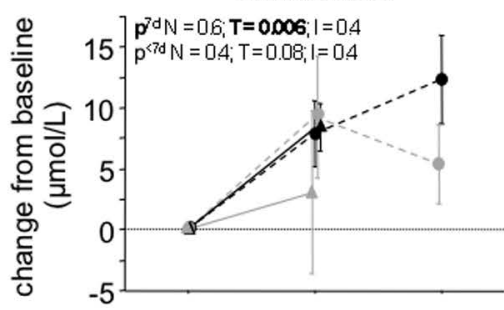

Phenylalanine

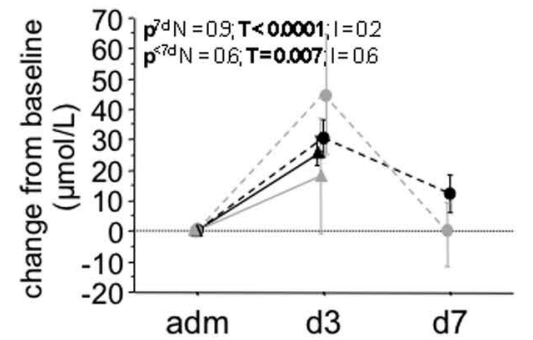

EAA

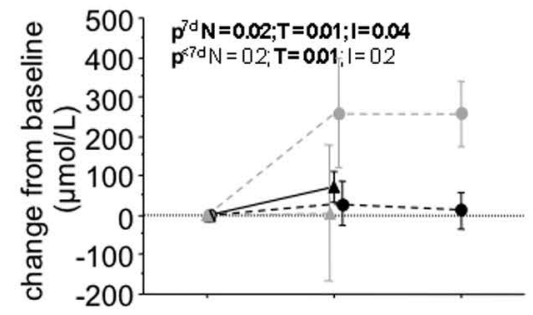

Serine

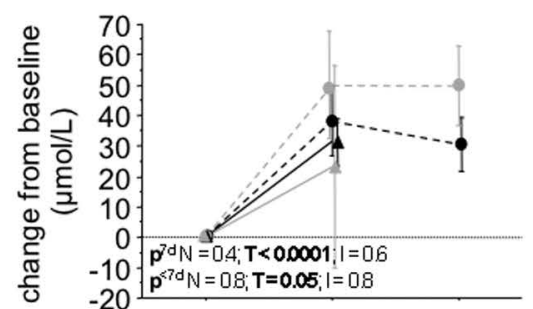

Taurine

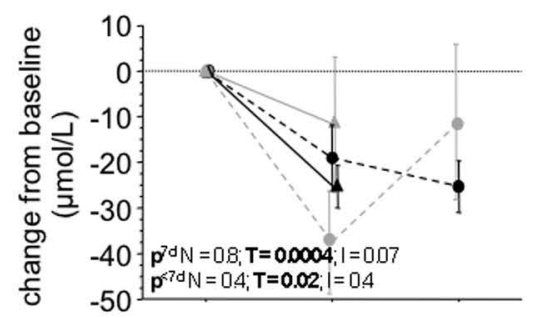

Threonine

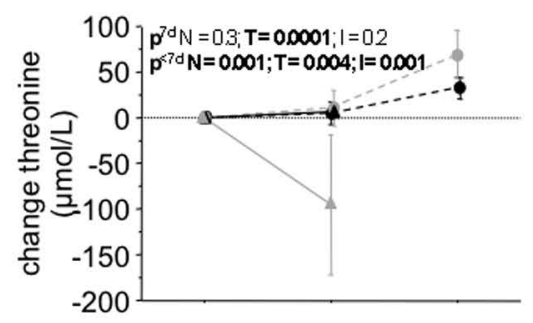

Tryptophan

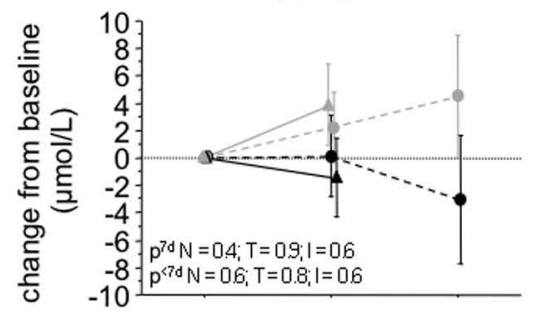

Tyrosine

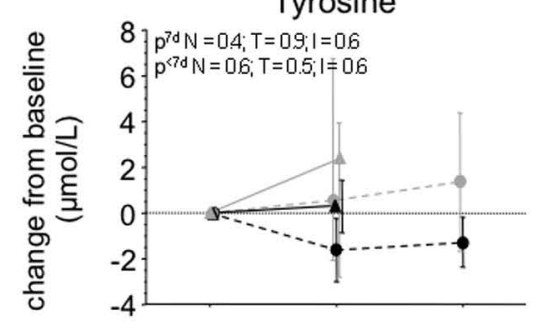

Valine

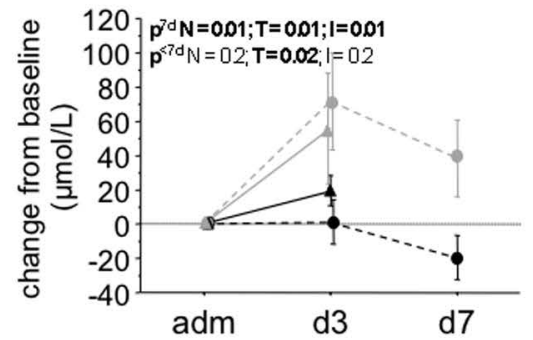




\section{Supplemental Digital Content Table 1: Baseline characteristics, treatment in ICU and outcome of the patients}

\section{Cardiac surgery intervention $\quad$ n}

Aortic arch reconstruction, with or without closure of ventricular septum defect 2

Assist devices for acute heart failure due to myocarditis or other cardiomyopathy 3

$\begin{array}{ll}\text { Closure aortopulmonary window } & 1\end{array}$

Closure of ventricular rupture $\quad 1$

Coarctectomy 3

Correction double outlet right ventricle 1

Correction of valvular or subvalvular stenosis of the aortic valve 4

Correction of valvular or subvalvular stenosis of the aortic valve and mitral valvuloplasty 1

Correction one or more septum defects $\quad 29$ inclusive atrial septum defect, ventricular septum defect and atrioventricular canal defect, with or without banding/debanding/valvular vitia/reconstruction aortic arch

Correction tetralogy of Fallot simple or with major aortopulmonary collateral arteries, first surgery or redo

Correction total anomalous pulmonary venous return 5

Correction transposition of the great arteries 6 arterial switch with or without correction septum defect

Damus-Kaye-Stensel Norwood with placement ECMO 1

Fontan/Glenn circuits 18

simple or with correction of other congenital anomalies, first surgery or redo

$\begin{array}{ll}\text { Mitral valvuloplasty } & 1\end{array}$

Modified Blalock-Taussig shunt 1

Norwood surgery and Fontan/Glenn circuits 1

Norwood surgery 1

Pulmonary artery banding 3

Rastelli or Nikaidoh 3

Right ventricular outflow tract reconstruction 1

ECMO: Extracorporeal membrane oxygenation. 
Supplemental Digital Content Table 2: Amino acid concentrations during intensive care unit stay

\begin{tabular}{|c|c|c|c|c|c|c|c|c|}
\hline $\begin{array}{c}\text { Amino acid } \\
\mu \mathrm{mol} / \mathrm{L}\end{array}$ & $\begin{array}{l}\text { Day in ICU } \\
\text { Day } 3 \\
\text { Day } 7\end{array}$ & $\begin{array}{l}\text { All data } \\
n=100 \\
n=40\end{array}$ & $\begin{array}{c}\text { Survivors } \\
\mathrm{n}=90 \\
\mathrm{n}=31\end{array}$ & $\begin{array}{c}\text { Non-survivors } \\
\mathrm{n}=10 \\
\mathrm{n}=9\end{array}$ & $\begin{array}{c}\text { Age } \leq \mathbf{4} \text { weeks } \\
\mathrm{n}=15 \\
\mathrm{n}=10\end{array}$ & $\begin{array}{c}\text { Age }>\text { (4 weeks } \\
\mathrm{n}=85 \\
\mathrm{n}=30\end{array}$ & $\begin{array}{l}\text { CIT } \\
\mathrm{n}=50 \\
\mathrm{n}=20\end{array}$ & $\begin{array}{l}\text { IIT } \\
\mathrm{n}=50 \\
\mathrm{n}=20\end{array}$ \\
\hline \multirow[t]{3}{*}{ Alanine } & Admission & $248 \pm 101$ & $234 \pm 74$ & $376 \pm 194$ & $315 \pm 118$ & $236 \pm 93$ & $243 \pm 98$ & $253 \pm 105$ \\
\hline & Day 3 & $205 \pm 102$ & $194 \pm 79$ & $300 \pm 200$ & $243 \pm 149$ & $198 \pm 90$ & $216 \pm 122$ & $194 \pm 79$ \\
\hline & Day 7 & $237 \pm 106$ & $207 \pm 73$ & $339 \pm 140$ & $325 \pm 108$ & $207 \pm 89^{a}$ & $237 \pm 115$ & $236 \pm 99$ \\
\hline \multirow[t]{3}{*}{ Arginine } & Admission & $45 \pm 17$ & $45 \pm 16$ & $44 \pm 23$ & $35 \pm 14$ & $47 \pm 17$ & $43 \pm 17$ & $47 \pm 17$ \\
\hline & Day 3 & $44 \pm 15$ & $44 \pm 15$ & $43 \pm 14$ & $44 \pm 13$ & $43 \pm 16$ & $43 \pm 13$ & $44 \pm 17$ \\
\hline & Day 7 & $54 \pm 20$ & $51 \pm 21$ & $64 \pm 16$ & $66 \pm 21$ & $50 \pm 19$ & $55 \pm 20$ & $53 \pm 21$ \\
\hline \multirow[t]{3}{*}{ Asparagine } & Admission & $29 \pm 10$ & $29 \pm 10$ & $31 \pm 13$ & $26 \pm 8$ & $30 \pm 11$ & $28 \pm 10$ & $30 \pm 11$ \\
\hline & Day 3 & $25 \pm 12$ & $24 \pm 11$ & $33 \pm 17$ & $25 \pm 15$ & $25 \pm 12$ & $25 \pm 12$ & $25 \pm 13$ \\
\hline & Day 7 & $26 \pm 11$ & $24 \pm 9$ & $33 \pm 14$ & $29 \pm 15$ & $25 \pm 9$ & $28 \pm 12$ & $24 \pm 9$ \\
\hline \multirow[t]{3}{*}{ Glutamine } & Admission & $397 \pm 114$ & $396 \pm 115$ & $410 \pm 110$ & $344 \pm 107$ & $407 \pm 113^{a}$ & $396 \pm 121$ & $399 \pm 108$ \\
\hline & Day 3 & $351 \pm 99$ & $347 \pm 98$ & $383 \pm 110$ & $330 \pm 102$ & $354 \pm 99$ & $355 \pm 87$ & $346 \pm 110$ \\
\hline & Day 7 & $368 \pm 111$ & $346 \pm 95$ & $441 \pm 135$ & $402 \pm 145$ & $356 \pm 97$ & $385 \pm 100$ & $351 \pm 121$ \\
\hline \multirow[t]{3}{*}{ Glutamate } & Admission & $139 \pm 74$ & $134 \pm 68$ & $182 \pm 108$ & $130 \pm 43$ & $141 \pm 78$ & $142 \pm 80$ & $135 \pm 68$ \\
\hline & Day 3 & $126 \pm 53$ & $122 \pm 49$ & $167 \pm 70$ & $168 \pm 55$ & $118 \pm 49^{a}$ & $141 \pm 56$ & $113 \pm 45^{a}$ \\
\hline & Day 7 & $140 \pm 56$ & $133 \pm 56$ & $162 \pm 52$ & $179 \pm 40$ & $127 \pm 55^{a}$ & $162 \pm 63$ & $118 \pm 38^{a}$ \\
\hline \multirow[t]{3}{*}{ Glycine } & Admission & $208 \pm 75$ & $205 \pm 70$ & $231 \pm 113$ & $276 \pm 90$ & $195 \pm 66^{a}$ & $192 \pm 55$ & $223 \pm 89$ \\
\hline & Day 3 & $229 \pm 87$ & $219 \pm 73$ & $316 \pm 143$ & $291 \pm 106$ & $218 \pm 79^{a}$ & $230 \pm 100$ & $228 \pm 73$ \\
\hline & Day 7 & $302 \pm 128$ & $279 \pm 104$ & $380 \pm 175$ & $370 \pm 120$ & $279 \pm 124^{a}$ & $297 \pm 126$ & $306 \pm 133$ \\
\hline \multirow[t]{3}{*}{ Histidine } & Admission & $75 \pm 34$ & $71 \pm 17$ & $108 \pm 93$ & $73 \pm 21$ & $75 \pm 36$ & $76 \pm 45$ & $74 \pm 20$ \\
\hline & Day 3 & $73 \pm 23$ & $71 \pm 20$ & $96 \pm 33$ & $80 \pm 26$ & $72 \pm 22$ & $71 \pm 24$ & $76 \pm 22$ \\
\hline & Day 7 & $70 \pm 23$ & $65 \pm 24$ & $84 \pm 15$ & $71 \pm 15$ & $69 \pm 25$ & $68 \pm 23$ & $71 \pm 24$ \\
\hline \multirow[t]{3}{*}{ Isoleucine } & Admission & $51 \pm 20$ & $50 \pm 19$ & $53 \pm 27$ & $42 \pm 16$ & $52 \pm 20$ & $49 \pm 17$ & $52 \pm 22$ \\
\hline & Day 3 & $62 \pm 19$ & $61 \pm 18$ & $74 \pm 21$ & $71 \pm 25$ & $61 \pm 17$ & $62 \pm 19$ & $63 \pm 19$ \\
\hline & Day 7 & $53 \pm 15$ & $53 \pm 16$ & $55 \pm 15$ & $49 \pm 15$ & $54 \pm 15$ & $53 \pm 17$ & $53 \pm 14$ \\
\hline \multirow[t]{3}{*}{ Leucine } & Admission & $107 \pm 38$ & $107 \pm 36$ & $111 \pm 52$ & $94 \pm 34$ & $109 \pm 38$ & $105 \pm 28$ & $109 \pm 46$ \\
\hline & Day 3 & $99 \pm 31$ & $97 \pm 26$ & $121 \pm 55$ & $117 \pm 49$ & $96 \pm 25^{a}$ & $103 \pm 36$ & $96 \pm 24$ \\
\hline & Day 7 & $98 \pm 37$ & $87 \pm 25$ & $135 \pm 48$ & $132 \pm 51$ & $86 \pm 21^{a}$ & $103 \pm 46$ & $93 \pm 24$ \\
\hline
\end{tabular}




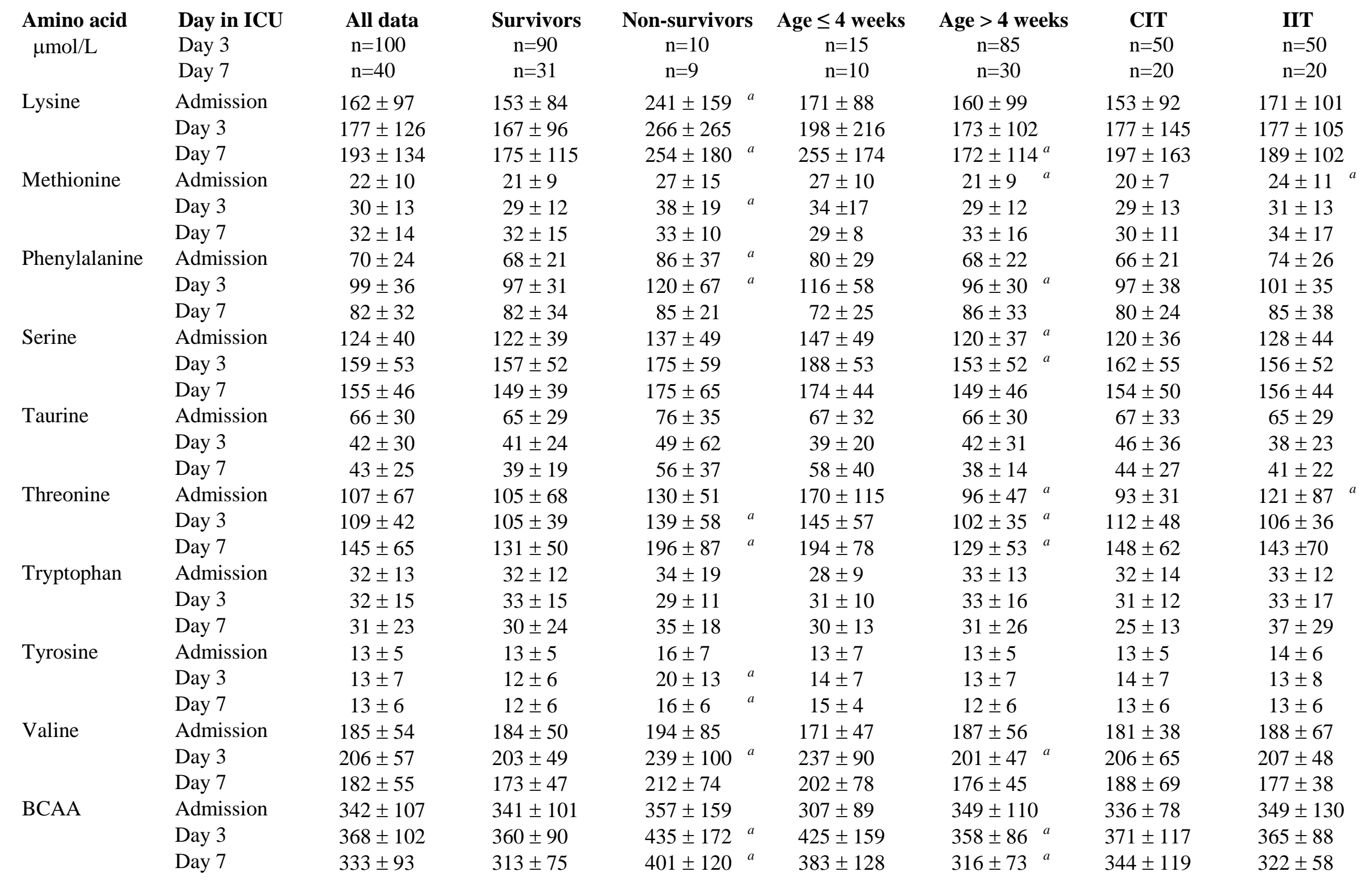




\begin{tabular}{|c|c|c|c|c|c|c|c|c|}
\hline $\begin{array}{l}\text { Amino acid } \\
\mu \mathrm{mol} / \mathrm{L}\end{array}$ & $\begin{array}{l}\text { Day in ICU } \\
\text { Day } 3 \\
\text { Day } 7\end{array}$ & $\begin{array}{l}\text { All data } \\
n=100 \\
n=40\end{array}$ & $\begin{array}{c}\text { Survivors } \\
\qquad \begin{array}{c}n=90 \\
n=31\end{array}\end{array}$ & $\begin{array}{c}\text { Non-survivors } \\
\qquad \begin{array}{c}n=10 \\
n=9\end{array}\end{array}$ & $\begin{array}{c}\text { Age } \leq \mathbf{4} \text { weeks } \\
n=15 \\
n=10\end{array}$ & $\begin{array}{c}\text { Age }>4 \text { weeks } \\
n=85 \\
n=30\end{array}$ & $\begin{array}{l}\text { CIT } \\
n=50 \\
n=20\end{array}$ & $\begin{array}{l}\text { IIT } \\
n=50 \\
n=20\end{array}$ \\
\hline \multirow[t]{3}{*}{ EAA } & Admission & $811 \pm 245$ & $792 \pm 217$ & $984 \pm 394$ & $855 \pm 287$ & $803 \pm 238$ & $775 \pm 199$ & $848 \pm 282$ \\
\hline & Day 3 & $891 \pm 289$ & $864 \pm 225$ & $1121 \pm 581$ & $1029 \pm 499$ & $865 \pm 226$ & $888 \pm 339$ & $894 \pm 234$ \\
\hline & Day 7 & $886 \pm 261$ & $827 \pm 210$ & $1088 \pm 326$ & $1032 \pm 339$ & $837 \pm 214$ & $890 \pm 314$ & $881 \pm 203$ \\
\hline \multirow[t]{3}{*}{ NEAA } & Admission & $1268 \pm 317$ & $1242 \pm 279$ & $1501 \pm 513$ & $1353 \pm 324$ & $1253 \pm 316$ & $1244 \pm 296$ & $1293 \pm 339$ \\
\hline & Day 3 & $1196 \pm 338$ & $1163 \pm 291$ & $1486 \pm 549$ & $1343 \pm 432$ & $1169 \pm 314$ & $1232 \pm 357$ & $1162 \pm 319$ \\
\hline & Day 7 & $1337 \pm 383$ & $1241 \pm 261$ & $1667 \pm 550^{a}$ & $1618 \pm 457$ & $1243 \pm 311^{a}$ & $1374 \pm 392$ & $1299 \pm 381$ \\
\hline \multirow[t]{3}{*}{ Sum } & Admission & $2079 \pm 518$ & $2033 \pm 447$ & $2485 \pm 876^{a}$ & $2208 \pm 572$ & $2056 \pm 508$ & $2019 \pm 451$ & $2137 \pm 575$ \\
\hline & Day 3 & $2081 \pm 593$ & $2020 \pm 485$ & $2607 \pm 1080^{a}$ & $2372 \pm 910$ & $2028 \pm 506^{a}$ & $2120 \pm 662$ & $2044 \pm 525$ \\
\hline & Day 7 & $2223 \pm 585$ & $2068 \pm 424$ & $2755 \pm 7644^{a}$ & $2650 \pm 691$ & $2080 \pm 478^{a}$ & $2265 \pm 630$ & $2180 \pm 550$ \\
\hline
\end{tabular}

CIT: conventional insulin therapy, IIT: intensive insulin therapy, BCAA: branched-chain amino acids, EAA: essential amino acids, NEAA: non-essential amino acids. ${ }^{a} p \leq 0.05$ in unpaired t-test or Mann-Whitney $\mathrm{U}$ on the respective day for survivors versus non-survivors, neonates versus children older than 4 weeks, or CIT versus IIT. 